\title{
Parking pricing vs. congestion pricing \\ A macroscopic analysis of their impact on traffic
}

\section{Working Paper}

Author(s):

Jakob, Manuel; Menendez, Monica

Publication date:

2020-05

Permanent link:

https://doi.org/10.3929/ethz-b-000417542

Rights / license:

In Copyright - Non-Commercial Use Permitted

Originally published in:

SVT Working Papers 


\section{Parking Pricing vs. Congestion Pricing: A Macroscopic Analysis of their Impact on Traffic}

Manuel Jakob $^{\mathrm{a} *}$, Monica Menendez

${ }^{a}$ Institute for Transport Planning and Systems (IVT), ETH Zürich, Zurich, Switzerland;

${ }^{b}$ Associate Professor of Civil and Urban Engineering, Division of Engineering, New York University Abu Dhabi (NYUAD), United Arab Emirates

*Corresponding Author:

Manuel Jakob

Stefano-Franscini-Platz 5

8093 Zurich

Switzerland

Phone: +4915110831281

Email: manuel.jakob@ivt.baug.ethz.ch

Paper word count: 11,340 words 


\section{Parking Pricing vs. Congestion Pricing: A Macroscopic Analysis of their Impact on Traffic}

As traffic congestion gets worse year by year in metropolitan areas, cities search for solutions to improve their traffic performance and reduce their environmental impacts. This paper focuses on parking pricing and congestion pricing and their short-term effects not only on traffic congestion but also on the potential revenue for a city.

We develop an easy to implement multimodal macroscopic traffic and parking search model for a central area based on aggregated data at the network level. Our methodology allows us to analyze how introducing parking pricing inside a network, or a congestion toll combined with a park and ride $(\mathrm{P}+\mathrm{R})$ scheme can affect the drivers' decision between entering the network by car (private vehicle) or using $\mathrm{P}+\mathrm{R}$ instead. This decision directly influences the number of drivers using $\mathrm{P}+\mathrm{R}$, and this impacts, in turn, the traffic performance. Based on such analysis, a city can get valuable insights to evaluate whether congestion pricing is a necessity or if the traffic improvements resulting from implementing parking pricing strategies are sufficient when combined with $\mathrm{P}+\mathrm{R}$ facilities. A search algorithm is used to find the best trade-off between the parking fees and the congestion toll. Any additional revenue collected through these schemes can then be used to improve public transport or the $\mathrm{P}+\mathrm{R}$ facilities themselves. With minor data collection efforts and little computational costs compared to most existing parking and congestion pricing models, we illustrate our proposed framework in a case study of an area with a high parking demand for public parking spaces within the city of Zurich, Switzerland. Results show that parking pricing combined with $\mathrm{P}+\mathrm{R}$ is indeed a viable option compared to congestion pricing for improving traffic performance, even if parking pricing schemes do not target all the drivers.

Keywords: parking pricing; congestion pricing; park and ride; dynamic macroscopic traffic and parking model; cruising-for-parking 


\section{Introduction}

Traffic congestion is a growing challenge for cities worldwide. Therefore, many city councils have considered introducing a congestion charge to improve speeds and reduce congestion in downtown areas. The first cities to introduce an electronic road pricing system with a combination of cordon and corridor pricing schemes were Singapore

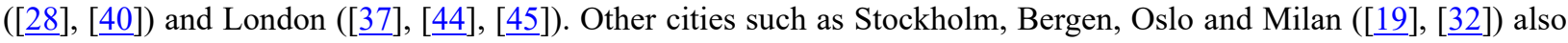
implemented similar schemes. However, the introduction of congestion pricing has not been successful so far in other areas such as Hong Kong ([3]]). New York City rejected its congestion pricing proposal in 2008, but new efforts in 2019 will lead New York to become the first city in the U.S. to implement a traffic congestion fee by 2021 ([29], [31], [46]). Overall, the actual implementation of congestion pricing schemes is rather limited due to the controversial issues regarding the high initial costs, problems of discrimination, and where to start the border. There are also many debates in relation to the disposition of the revenues raised, undesirable distribution effects, and the social and political acceptability of the congestion charge ([]], [15], [48]). In this research, we analyze the differences in traffic performance driven by parking pricing policies as a comparable option to congestion pricing. Parking pricing strategies can be easily installed and maintained by a city, and they normally face much less political opposition ([5]). In addition, their introduction can lead to remarkable traffic performance improvements ([5] , [12], [34], [50]). However, parking pricing policies only affect drivers using public parking in the area compared to congestion pricing policies affecting a larger group of drivers in the network (e.g., drivers using private parking, drivers passing through the central area, drivers picking up and/or dropping off passengers). That being said, when the share of drivers searching for public parking is large enough, parking pricing could indeed be considered as a viable alternative to congestion pricing. In this paper, we take these trade-offs into account, so cities can use our methodology to evaluate the parking and congestion pricing policies especially in areas with a high parking demand for public parking spaces. We propose a macroscopic framework to evaluate the short-term performance of an urban network under the implementation of parking pricing policies as an alternative to a congestion pricing scheme.

All the congestion pricing methodologies implemented so far are based on the principle of marginal cost pricing. A comprehensive literature summary of congestion pricing models can be found in [드] . Some models determine the congestion charge focusing on the time loss externalities for drivers not entering the network ([4]], [뇨], [ $\underline{53}]$ ). If a city introduces congestion pricing, alternative transportation options should also be offered. Therefore, it is reasonable for cities to reinvest the income from congestion pricing onto other modes. [37] and [43] investigated the impact on the traffic performance and the changes in congestion driven by the changes in modal split triggered by the congestion pricing. These studies used aggregated traffic indicators, but did not take into account any parking related phenomena. The methodology we propose in this paper allows us to model the decision of entering the area and paying the congestion charge or not entering and changing the transportation mode at a park and ride $(\mathrm{P}+\mathrm{R})$ facility outside the area. In the latter case the drivers then use some form of public transportation (PT) to enter the protected area, e.g., buses, trams and/or trains. [1] examines the sensitivity of drivers' attitudes towards parking fees and congestion tolls and their effect on travel habits such as demand changes for the considered network. In comparison to our macroscopic methodology, a numerical simulation model is developed in [13] to study the efficiency gains from various parking policies with and without a simple cordon pricing scheme. [2] used empirical data from loop detectors and automated vehicle location (AVL) devices from May 2016 to analyze the impacts of London's congestion pricing using the multimodal extension of the macroscopic fundamental diagram (MFD ([25], [26], [27])), the 3D-MFD ([17], [38],

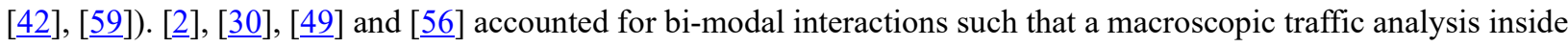
and outside the congestion pricing area could be made. Our research, in comparison, studies the short-term interdependencies between traffic congestion, $\mathrm{P}+\mathrm{R}$ and parking pricing within the area. The aggregated bi-modal interactions in [2] were observed for a large-scale network, and they did not account for the parking impacts within 
the area nor any $\mathrm{P}+\mathrm{R}$. In contrast, our methodology considers networks with traffic and parking systems that are affected by the drivers entering the area and searching for a parking space to get to their desired destination. These destinations can be within or outside our area of interest and since the cars start to search for parking within the area, their origin is irrelevant. Additionally, our macroscopic model can be easily solved with a simple numerical solver such as Excel or Matlab without the use of complex simulation software.

The contributions of this paper are fourfold. First, we evaluate how parking and congestion pricing affect the traffic and parking system (i.e., traffic performance, parking availability, revenue for the city, etc.) and how the traffic and parking system (i.e., traffic congestion, parking pricing, etc.) affect the drivers' decision between entering the network by car or using $\mathrm{P}+\mathrm{R}$ instead. Second, we propose a decision model and integrate it into a multimodal macroscopic traffic and parking framework focusing on parking and congestion pricing. This decision is faced by multiple user groups with respect to their value of time (VOT). This allows us to evaluate the distributional effects of different VOTs on the drivers' decision between entering the area by car or switching to $\mathrm{P}+\mathrm{R}$ instead. Third, we not only provide a framework to compare parking and congestion pricing scenarios, but also to find the best relation between the parking fee and the congestion charge in order to improve the traffic performance in the network or the total revenue for the city (which could be used to improve the $\mathrm{P}+\mathrm{R}$ facilities). Fourth, we illustrate our parking and congestion pricing methodology in a central area with a high parking demand for public parking spaces within the city of Zurich, Switzerland, and show that parking pricing is indeed a viable option compared to congestion pricing, potentially leading to traffic performance improvements inside the protected network.

The paper is organized as follows. Section 2 shows the overall decision model associated with the introduction of parking and congestion pricing to a central area. Section 3 illustrates the multimodal macroscopic traffic and parking framework including our decision model. Section 4 presents a case study of an area within the city of Zurich. Section 5 concludes this paper.

\section{Introducing parking pricing vs. congestion pricing policies for a central area}

In this section, we build the framework to compare the traffic performance impacts of different parking and/or congestion pricing policies. When introducing/increasing parking pricing within an area with no congestion pricing combined with $\mathrm{P}+\mathrm{R}$ facilities, the drivers face a new choice between entering the network and leaving their car outside the area, potentially using the available $\mathrm{P}+\mathrm{R}$ facilities and $\mathrm{PT}$ (i.e., bus, tram and/or train) to reach the center. A similar decision happens for drivers when congestion pricing gets introduced to a central area. Please note that we assume $\mathrm{P}+\mathrm{R}$ facilities exist in both policies.

In this research, we analyze the influencing factors (section 2.1) and the mathematical decision model (section 2.2) for two policies: parking pricing (policy 1) and congestion pricing (policy 2).

\subsection{Factors affecting the decision framework}

The main variables and parameters for our framework, and basic model assumptions are briefly described below.

Main variables and parameters:

All policies are modeled macroscopically using a logistic function based on the cost of entering the network by car and the cost of using the $\mathrm{P}+\mathrm{R}$ facility outside the network. Some factors including the congestion or parking charges have only an impact on the cost of entering the network, some factors including the $\mathrm{P}+\mathrm{R}$ pricing only affect the cost of not entering the network, and others (i.e., the number of parking spaces for $\mathrm{P}+\mathrm{R}$ and spaces inside the network) impact both cost variables by directly influencing the decision. Table 1 introduces the main variables and parameters 
used in our methodology.

Table 1. List of main variables and parameters.

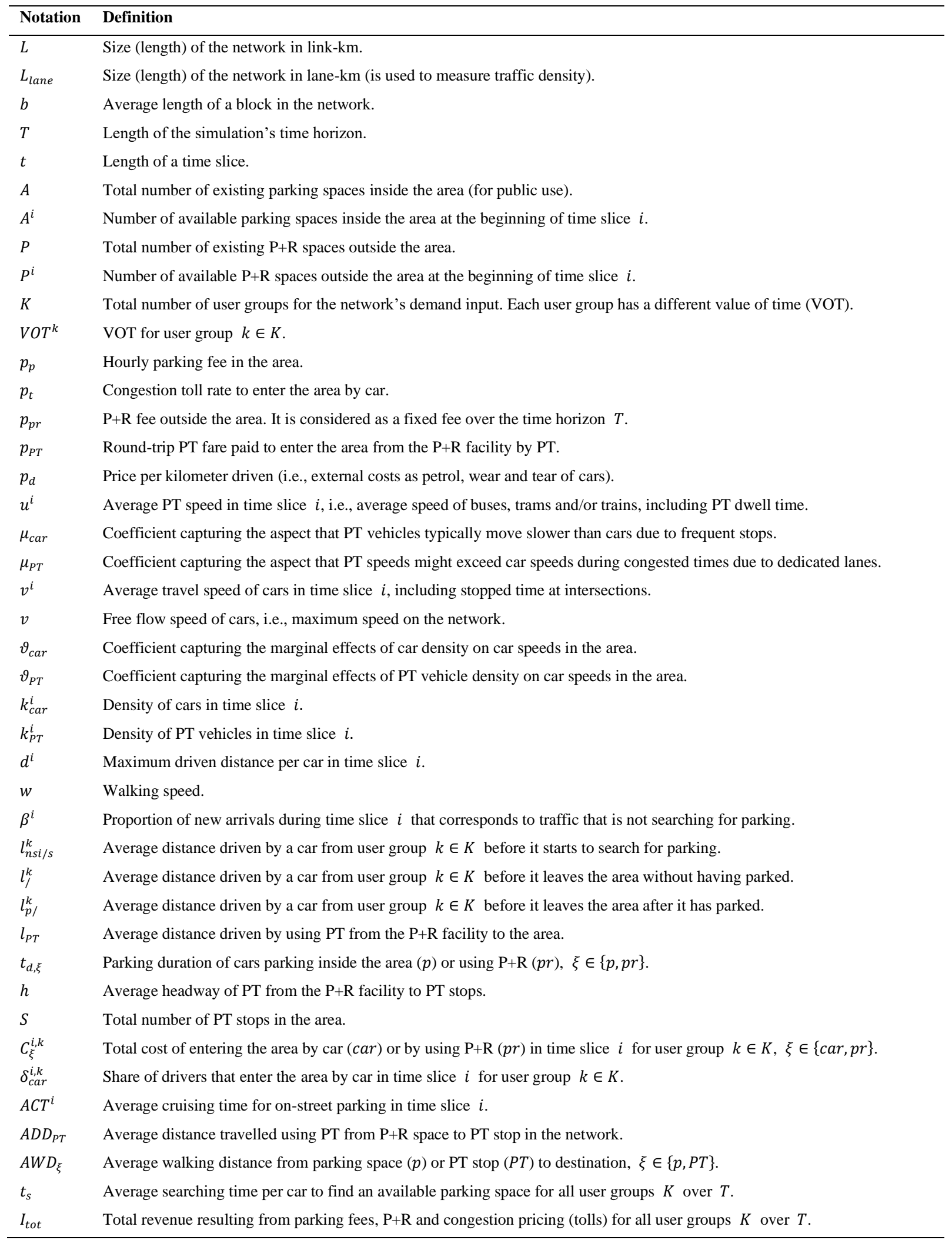

Our traffic model analyzes a homogeneous, compact urban network of length $L$ (in link-km) and $L_{\text {lane }}$ (in lane-km) representing a central area with standard parking policies (e.g., downtown areas or portions thereof) and a high parking 
demand for public parking spaces. The network's average block size is represented as $b$. It is simulated over a total time horizon $T$ (e.g., a day). This time period is divided into time slices $t$ (e.g., 1 minutes) such that the traffic and parking conditions are steady within each time slice, but they can change over multiple time slices. Drivers have different VOTs, $V O T^{k}$, according to their individual user group $k \in K$, with the total number of user groups denoted as $K$. This can be dependent on the drivers' residence location, income, career, working state, etc. Due to our macroscopic modelling approach it is not necessary to record the individual location of each car and parking space throughout time. Instead, our multimodal macroscopic traffic model (section 3.1) tracks the average number of cars during every time slice and the average searching times and traveled distances in the area.

\section{Assumptions about homogeneity:}

For simplicity, the area contains $A$ identical parking spaces inside, and $P \mathrm{P}+\mathrm{R}$ spaces outside the parking and congestion pricing area. A differentiation between on-street and garage parking can be added using the macroscopic modelling approach in [35], but here, for simplicity, we obviate that. All drivers searching for parking are assumed to be homogenously distributed within the overall traffic, and all parking spaces (not necessarily the available ones) are assumed to be uniformly distributed on the network.

\section{Assumptions about PT and mode choice:}

The PT route is assumed to be unidirectional (i.e., it goes on a loop around the network). The total number of PT stops is assumed to be uniformly distributed across the network and the actual travel distance of each PT passenger is on average uniformly distributed over time. Once the drivers have entered the network by car, it is assumed that they continue their trip with their car and do not change towards PT within the network. This is reasonable since the drivers already paid the congestion toll. We also assume that drivers do not cancel their trip.

\section{Assumptions about walking:}

After parking in or riding a bus into the area, the drivers require some walking distance to reach their final destination. The drivers' walking speed, $w$, is assumed to be constant. At an earlier stage, the drivers switching to $\mathrm{P}+\mathrm{R}$ already require some walking distance between the parking space and the PT stop near the P+R facility which is assumed to be negligible for our decision framework.

\section{Assumptions about pricing and toll delays:}

The hourly parking fee $p_{p}$, the congestion toll rate $p_{t}$, the $\mathrm{P}+\mathrm{R}$ fee $p_{p r}$, and the round-trip PT fare $p_{P T}$ are assumed to be constant over time. There is no traffic delay assumed while paying the congestion toll.

\subsection{Mathematical model for the parking and congestion pricing decision framework}

This section illustrates the mathematical decision framework for drivers entering the network by car or choosing to use $\mathrm{P}+\mathrm{R}$ instead. The model can be used for both policies explained before, so that we can compare and analyze the traffic performance under different scenarios.

Drivers' choice, $\delta_{\text {car }}^{i, k}$, for entering the area by car is modelled in Eq. (1a-b) using a logistic function based on $A$ and $P$ (the total number of existing parking and $\mathrm{P}+\mathrm{R}$ spaces, respectively), $C_{c a r}^{i, k}$ (the total cost of entering the area by car, modelled in section 2.2.1), and $C_{p r}^{i, k}$ (the total cost of using P+R, modelled in section 2.2.2) in time slice $i$ for user group $k \in K$.

$$
\delta_{c a r}^{i, k}=\frac{e^{\eta^{i, k}}}{1+e^{\eta^{i, k}}}
$$


where

$$
\eta^{i, k}=\frac{\frac{A}{A+P} \cdot C_{p r}^{i, k}-\frac{P}{A+P} \cdot C_{c a r}^{i, k}}{\min \left\{\frac{A}{A+P} \cdot C_{p r}^{i, k}, \frac{P}{A+P} \cdot C_{c a r}^{i, k}\right\}}
$$

The drivers' choice between entering the area by car or by using $\mathrm{P}+\mathrm{R}$ is based on the comparison between the weighted cost variables $\frac{A}{A+P} \cdot C_{p r}^{i, k}$ and $\frac{P}{A+P} \cdot C_{c a r}^{i, k}$ in Eq. (1b). Their difference is set in relation to $\min \left\{\frac{A}{A+P} \cdot C_{p r}^{i, k}, \frac{P}{A+P} \cdot C_{c a r}^{i, k}\right\}$ as the drivers' choice is based on a relative weighted cost difference. Using the minimum here is necessary to set a reference to the lowest cost value. The weight parameters $\frac{A}{A+P}$ and $\frac{P}{A+P}$ in Eq. (1b) illustrate the parking supply dependency incorporated into the parking choice. An underlying assumption for Eq. (1a-b) is that all drivers have access to information about $A, P$ and the basic data to estimate $C_{c a r}^{i, k}$ and $C_{p r}^{i, k}$. However, drivers have, for simplicity, no access to real-time parking usage information, i.e., we only consider the total number of existing parking and $\mathrm{P}+\mathrm{R}$ spaces, $A$ and $P$, respectively; and we do not use the time-dependent parking availabilities in Eq. (1b). This information could, however, be added to this model as per the methodology proposed in [35] to account for the value of real-time parking information.

\subsubsection{Cost of entering the network by car}

Eq. (2) describes the cost of entering the network by car, $C_{c a r}^{i, k}$, for each user group $k \in K$ in time slice $i$.

$$
C_{\text {car }}^{i, k}=\underbrace{p_{t}}_{\text {term } 1}+\underbrace{p_{p} \cdot E\left(f\left(t_{d, p}\right)\right)}_{\text {term } 2}+\underbrace{p_{d} \cdot v^{i} \cdot A C T^{i}}_{\text {term } 3}+\underbrace{V O T^{k} \cdot\left(\frac{l_{n s i / s}^{k}}{v^{i}}+A C T^{i}+\frac{2 \cdot A W D_{p}}{w}+\frac{l_{p /}^{k}}{v^{i}}\right)}_{\text {term } 4}
$$

Term 1 represents the congestion toll rate (policy 2), $p_{t}$. Term 2 represents the total parking charge (policy 1), which is dependent on the hourly parking fee, $p_{p}$, and the expected parking duration, $E\left(f\left(t_{d, p}\right)\right)$. While this fee will be fixed here, it is also possible to make it variable using a responsive parking pricing scheme ([ㅍu]). Term 3 represents the average cost associated with the cruising distance for parking (i.e., external costs as petrol, wear and tear of cars) converted to price units ([35] $)$. The average cruising time $A C T^{i}$ is determined as in [34] using a queueing diagram. The price per kilometer driven is denoted as $p_{d}$ and the average travel speed in time slice $i$ is represented as $v^{i}$. Here, for simplicity, we assume that $v^{i}$ is representative of the average network speed during the future search process. Term 4 represents the time-related costs based on the drivers' VOT expressed in price units for $k \in K$. It includes the costs associated with the average distance before starting to search for parking $l_{n s i / s}^{k}$, the average cruising time $A C T^{i}$, the average walking distance $A W D_{p}$ from the parking space to the final destination, and the average distance to leave the area after parking $l_{p /}^{k}$. We multiply $A W D_{p}$ by 2 to account for the return trip to the car as well. Notice that the longer the drivers search for parking, the higher $A C T^{i}$ is, and consequently also $C_{c a r}^{i, k}$. In this case, it is more likely that the drivers might decide to use $\mathrm{P}+\mathrm{R}$ instead of entering the area by car. Using the abstraction of the network as a square grid, its total length, $L$, is equivalent to joining all blocks of average known length $b$ together. As parking spaces are uniformly distributed throughout the area, $A W D_{p}$ is determined in Eq. (3) as the average Manhattan distance between two random points in the square grid ([35], [41]). 


$$
A W D_{p}=\frac{2}{3} \cdot \underbrace{b \cdot\left(-\frac{1}{2}+\sqrt{\frac{1}{4}+\frac{L}{2 b}}\right)}_{\text {term } 1}
$$

Term 1 represents the side length of the square grid.

\subsubsection{Cost of using $P+R$}

Eq. (4) describes the cost of not entering the area by car and using $\mathrm{P}+\mathrm{R}$ instead, $C_{p r}^{i, k}$, for each user group $k \in K$ in time slice $i$. Notice that for a case where there are different areas with large variations in $\mathrm{P}+\mathrm{R}$ and PT properties (e.g., in PT stops, $\mathrm{P}+\mathrm{R}$ fees, $\mathrm{PT}$ fares, or dwell times), one can use different adjacent subnetworks, each modeled as the network presented here.

$$
C_{p r}^{i, k}=\underbrace{p_{p r}+p_{P T}}_{\text {term } 1}+\underbrace{V O T^{k} \cdot\left(h+\frac{2 \cdot A D D_{P T}}{u^{i}}+\frac{2 \cdot A W D_{P T}}{w}\right)}_{\text {term } 2}
$$

Term 1 represents the total fee, including the $\mathrm{P}+\mathrm{R}$ fee, $p_{p r}$, and the round-trip PT fare, $p_{P T}$, for buses, trams and/or trains from the $\mathrm{P}+\mathrm{R}$ facility. Note that the $\mathrm{P}+\mathrm{R}$ fee is fixed over the time horizon $T$. This is often the case, for example in cities like Zurich, Switzerland. However, this is not necessary for our model, as we can adapt term 1 according to, e.g., an hourly $\mathrm{P}+\mathrm{R}$ pricing rate. In some instances, $p_{p r}$ could also be zero. Term 2 represents all the time-related costs expressed in price units to reach the driver's destination within the network and to return back to the parked car at the $\mathrm{P}+\mathrm{R}$ facility. Once the driver has parked the car at the $\mathrm{P}+\mathrm{R}$ space, he/she has to wait until the next $\mathrm{PT}$ vehicle arrives. This average waiting time is reflected by $h / 2$ for the one-way trip ( $h$ for the two-way trip), where $h$ is the average headway of the PT line connecting the P+R facility to the area. The average round-trip travel time for the PT ride is modelled by $2 \cdot A D D_{P T} / u^{i}$, where $A D D_{P T}$ represents the average distance travelled using PT and $u^{i}$ describes the average PT speed in the network (including dwell times). We model $u^{i}$ in Eq. (5) as a function of the car speed $v^{i}$ using the statistical model for the vehicle based 3D-MFD in [38]. The coefficients $\mu_{c a r}$ and $\mu_{P T}$ are to be estimated and calibrated depending on the network of interest. $\mu_{\text {car }}$ captures the reduction of speed for PT vehicles compared to cars due to frequent stops. $\mu_{P T}$ adjusts the PT vehicle speed based on network topology and PT network design (e.g., whether the PT vehicles use dedicated lanes and exceed car speeds during congested times or not).

$$
u^{i}=\mu_{c a r} \cdot v^{i}+\mu_{P T}
$$

$A D D_{P T}$ is computed in Eq. (6) by using the mean based on the round-trip PT travel distance in Fig. 1a. Given that the total length of the network is $L$ and the average block size is $b$, the network side is $b \cdot\left(-\frac{1}{2}+\sqrt{\frac{1}{4}+\frac{L}{2 b}}\right) . S$ is the total number of PT stops with an average distance of $\frac{b \cdot\left(-\frac{1}{2}+\sqrt{\frac{1}{4}+\frac{L}{2 b}}\right)}{\sqrt{S}}$ between any consecutive stops along the unidirectional PT route. The round-trip PT travel distance in Fig. 1a is computed according to [16] as the surface of the square grid $\left[b \cdot\left(-\frac{1}{2}+\sqrt{\frac{1}{4}+\frac{L}{2 b}}\right)\right]^{2}$ divided by $\frac{b \cdot\left(-\frac{1}{2}+\sqrt{\frac{1}{4}+\frac{L}{2 b}}\right)}{\sqrt{S}}$. Term 1 (Eq. (6)) is then determined as half of this result representing the average PT passenger's journey. Term 2 shows the average driven distance, $l_{P T}$, by using PT from the $\mathrm{P}+\mathrm{R}$ facilities to the area (Fig. 1a), which is a function of the network size. 


$$
A D D_{P T}=\underbrace{b \cdot \frac{\sqrt{S}}{2} \cdot\left(-\frac{1}{2}+\sqrt{\frac{1}{4}+\frac{L}{2 b}}\right)}_{\text {term } 1}+\underbrace{l_{P T}}_{\text {term } 2}
$$

As $S$ is limited, people are expected to require, on average, some walking time. The average round-trip walking time from the PT stop until the destination is modelled by $2 \cdot A W D_{P T} / w$ in term 2 (Eq. (4)), where the average walking distance, $A W D_{P T}$, is determined in Eq. (7).

$$
A W D_{P T}=\frac{2 b}{3 \sqrt{\pi \cdot S}}\left[-\frac{1}{2}+\sqrt{\frac{1}{4}+\frac{L}{2 b}}\right]
$$

To obtain Eq. (7), the surface $\left[b \cdot\left(-\frac{1}{2}+\sqrt{\frac{1}{4}+\frac{L}{2 b}}\right)\right]^{2}$ is divided by the number of PT stops, $S$, to estimate the area served by each PT stop (Fig. 1b). Assuming the drivers' destinations are uniformly distributed in the area we determine the average walking distance as $\frac{2}{3}$ of the radius (average distance from the center of a circle) of each of the areas surrounding one PT stop.

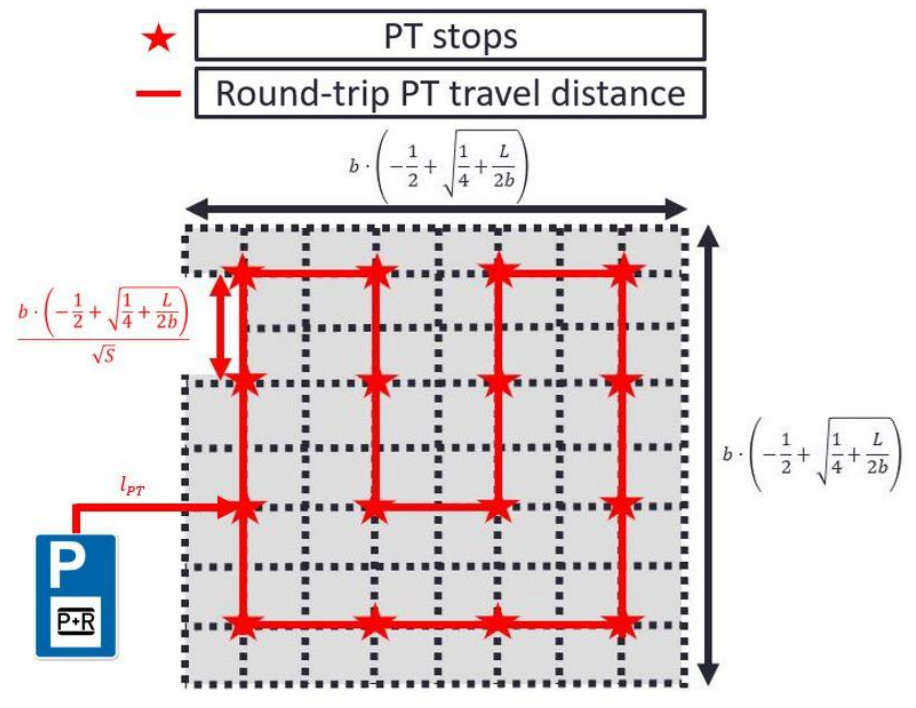

(a) Distance travelled using PT.

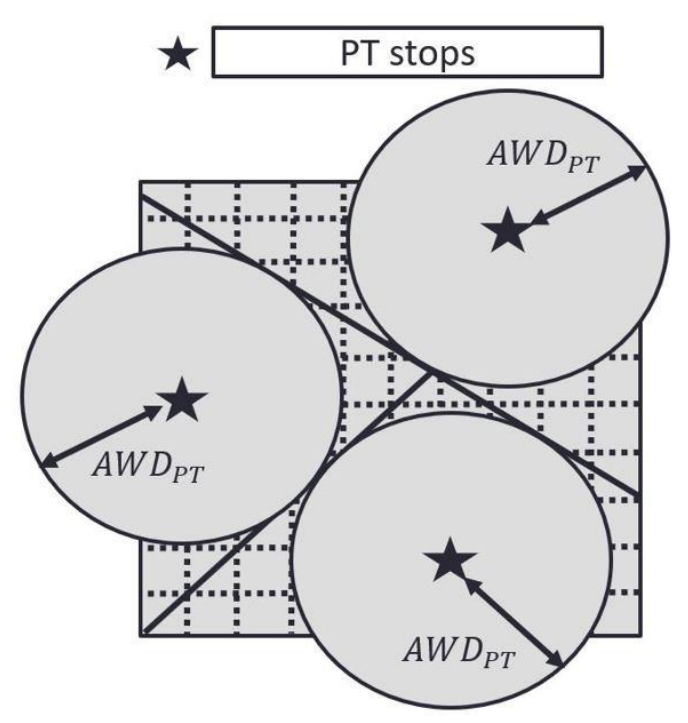

(b) Average walking distance for PT.

Fig. 1. Simple example of an abstracted square grid with uniformly distributed PT stops to illustrate $A D D_{P T}$ and $A W D_{P T}$.

It is possible to add a discomfort term to Eq. (4) for drivers using PT instead of using their more comfortable car to enter the area according to [됴. However, we omit such term in this paper for brevity.

\section{Parking and congestion pricing}

Introducing parking and congestion pricing can lead to traffic performance and/or revenue changes for an area. To compare and analyze these impacts both policies are integrated into a macroscopic urban traffic and parking framework.

In section 3.1, we propose a multimodal macroscopic traffic and parking model including the option of using $\mathrm{P}+\mathrm{R}$ instead of entering the network by car. In sections 3.2 and 3.3, we determine the traffic performance in the area and 
the total revenue for the city, respectively.

\subsection{A multimodal macroscopic traffic and parking framework focusing on parking and congestion pricing}

Increasing the parking fees or introducing a congestion toll might lead to less traffic within the area of interest. Our multimodal macroscopic traffic and parking model uses the 3D-MFD framework from [38] and [60] as a foundation to analyze that. We combine this 3D-MFD model with insights from the parking-state-based matrix framework, and the methodology to determine the likelihood of finding parking from [10]. The matrix is used to capture the system dynamics of urban car and $\mathrm{P}+\mathrm{R}$ traffic, i.e., it allows us to evaluate, for example, how the cars searching for parking or the drivers deciding to enter the area using $\mathrm{P}+\mathrm{R}$ affect the traffic performance and the congestion in the network.

Our model uses the five traffic states summarized in Table 2. Updating the traffic states is an iterative process until the end of the time horizon, or until a defined criterion is reached (e.g., all the cars leave the network). Notice that all state variables need an initial condition as an input to the model. That value can be measured, assumed or simulated.

Table 2. Traffic states for our multimodal macroscopic traffic and parking framework in an area of interest.

\begin{tabular}{lll}
\hline Notation & Name & Definition \\
\hline $\begin{array}{ll}N_{n s e}^{i, k} \\
N_{n s i}^{i, k}\end{array}$ & $\begin{array}{l}\text { Non-searching } \\
\text { (external destination) }\end{array}$ & $\begin{array}{l}\text { Number of cars not searching for parking with external destination (i.e., outside the area) for user } \\
\text { group } k \in K \text { at the beginning of time slice } i .\end{array}$ \\
\hline$N_{s}^{i, k}$ & Searching for parking & $\begin{array}{l}\text { Number of cars searching for parking within the area for user group } k \in K \text { at the beginning of time } \\
\text { slice } i .\end{array}$ \\
\hline$N_{p}^{i, k}$ & Parking & $\begin{array}{l}\text { Number of cars not searching for parking with internal destination (i.e., within the area) for user group } \\
k \in K \text { at the beginning of time slice } i .\end{array}$ \\
\hline$N_{p r}^{i, k}$ & Park + Ride (P+R) & Number of cars using P+R for user group $k \in K$ at the beginning of time slice $i$. \\
\hline
\end{tabular}

The traffic states are determined based on the transition events depicted in Fig. 2 and defined in Table 3.

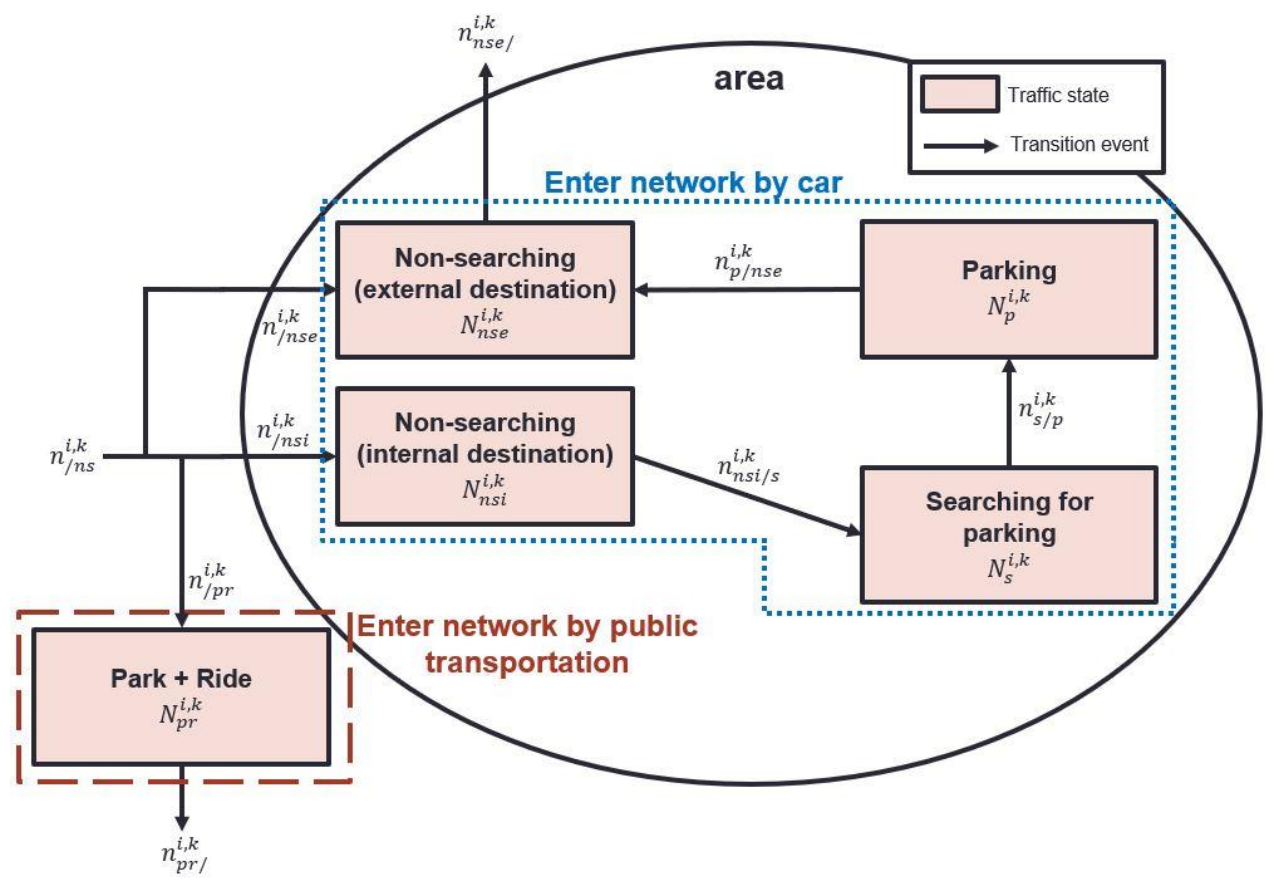

Fig. 2. The transition events in-between different traffic states in an area.

Fig. 2 illustrates two groups of drivers. The first group shows the drivers using a car to enter the network, with an 
internal or an external destination. The latter represents the through-traffic. For each user group $k \in K$, the throughtraffic enters the area and drives some distance $l_{/}^{k}$ ("non-searching (external destination)") before leaving the area. Once the cars focusing on internal destinations enter the area, they drive some distance $l_{n s i / s}^{k}$ towards their destination ("non-searching (internal destination)") before they search for an available parking space ("searching for parking"). After having parked for a given duration ("parking"), they travel some distance $l_{p /}^{k}$ to leave the area ("nonsearching (external destination)"). The second group of drivers decides to use PT to reach their destination inside the area from the $\mathrm{P}+\mathrm{R}$ facility ("Park + Ride"). They leave the $\mathrm{P}+\mathrm{R}$ spaces after having returned by PT from the area.

Table 3. Transition events for our multimodal macroscopic traffic and parking framework in an area of interest.

\begin{tabular}{|c|c|c|}
\hline Notation & Name & Definition \\
\hline$n_{/ \mathrm{ns}}^{i, k}$ & Enter the area & Number of cars entering the area by car and by $\mathrm{P}+\mathrm{R}$ for user group $k \in K$ during time slice $i$. \\
\hline$n_{/ n s e}^{i, k}$ & $\begin{array}{l}\text { Enter the area by car } \\
\text { (external destination) }\end{array}$ & $\begin{array}{l}\text { Number of cars entering and having their destination outside the area for user group } k \in K \\
\text { during time slice } i \text {. }\end{array}$ \\
\hline$n_{/ n s i}^{i, k}$ & $\begin{array}{l}\text { Enter the area by car } \\
\text { (internal destination) }\end{array}$ & $\begin{array}{l}\text { Number of cars entering and having their destination inside the area for user group } k \in K \text { during } \\
\text { time slice } i \text {. }\end{array}$ \\
\hline$n_{/ p r}^{i, k}$ & Enter the area by $\mathrm{P}+\mathrm{R}$ & Number of cars using $\mathrm{P}+\mathrm{R}$ to enter the area for user group $k \in K$ during time slice $i$. \\
\hline$n_{n s i / s}^{i, k}$ & $\begin{array}{l}\text { Start to search for } \\
\text { parking }\end{array}$ & $\begin{array}{l}\text { Number of cars starting to search for parking within the area for user group } k \in K \text { during time } \\
\text { slice } i \text {. }\end{array}$ \\
\hline$n_{s / p}^{i, k}$ & Access parking & Number of cars accessing parking within the area for user group $k \in K$ during time slice $i$. \\
\hline$n_{p / n s e}^{i, k}$ & Depart parking & $\begin{array}{l}\text { Number of cars departing from parking and moving towards a destination outside the area for user } \\
\text { group } k \in K \text { during time slice } i \text {. }\end{array}$ \\
\hline$n_{n s e /}^{i, k}$ & Leave the area by car & Number of cars leaving the area by car for user group $k \in K$ during time slice $i$. \\
\hline$n_{p r /}^{i, k}$ & Leave the area by $\mathrm{P}+\mathrm{R}$ & Number of cars leaving the area by $\mathrm{P}+\mathrm{R}$ for user group $k \in K$ during time slice $i$. \\
\hline
\end{tabular}

The traffic states (Table 2) are modelled in Eq. (8a-e) using the transition events (Table 3) according to Fig. 2.

$$
\begin{gathered}
N_{n s e}^{i+1}=\sum_{k=1}^{K} N_{n s e}^{i+1, k}, \text { where } N_{n s e}^{i+1, k}=N_{n s e}^{i, k}+n_{/ n s e}^{i, k}+n_{p / n s e}^{i, k}-n_{n s e}^{i, k} \\
N_{n s i}^{i+1}=\sum_{k=1}^{K} N_{n s i}^{i+1, k}, \text { where } N_{n s i}^{i+1, k}=N_{n s i}^{i, k}+n_{/ n s i}^{i, k}-n_{n s i / s}^{i, k} \\
N_{s}^{i+1}=\sum_{k=1}^{K} N_{s}^{i+1, k}, \text { where } N_{s}^{i+1, k}=N_{s}^{i, k}+n_{n s i / s}^{i, k}-n_{s / p}^{i, k} \\
N_{p}^{i+1}=\sum_{k=1}^{K} N_{p}^{i+1, k}, \text { where } N_{p}^{i+1, k}=N_{p}^{i, k}+n_{s / p}^{i, k}-n_{p / n s e}^{i, k} \\
N_{p r}^{i+1}=\sum_{k=1}^{K} N_{p r}^{i+1, k}, \text { where } N_{p r}^{i+1, k}=N_{p r}^{i, k}+n_{/ p r}^{i, k}-n_{p r /}^{i, k}
\end{gathered}
$$

All traffic states are determined for each user group $k \in K$ before aggregating them. The total number of cars parked for all user groups at the beginning of time slice $i$ is $N_{p}^{i}+N_{p r}^{i}$ (Eq. (8d-e)), whereas the total number of cars driving in the area at the beginning of time slice $i$ is $N_{n s e}^{i}+N_{n s i}^{i}+N_{s}^{i}$ (Eq. (8a-c)). The calculation of the traffic states in Eq. (8a-e) could be advanced by using an MFD simulator model approximating the dynamic user equilibrium 
conditions in large scale networks ([57]). These improvements, however, are considered out-of-scope for this paper. The traffic composition change (i.e., the change of the number of cars in each parking-related state) between two consecutive time slices can be illustrated in queuing diagrams for cars entering the area (Fig. 3a) and cars switching to $\mathrm{P}+\mathrm{R}$ (Fig. 3b).

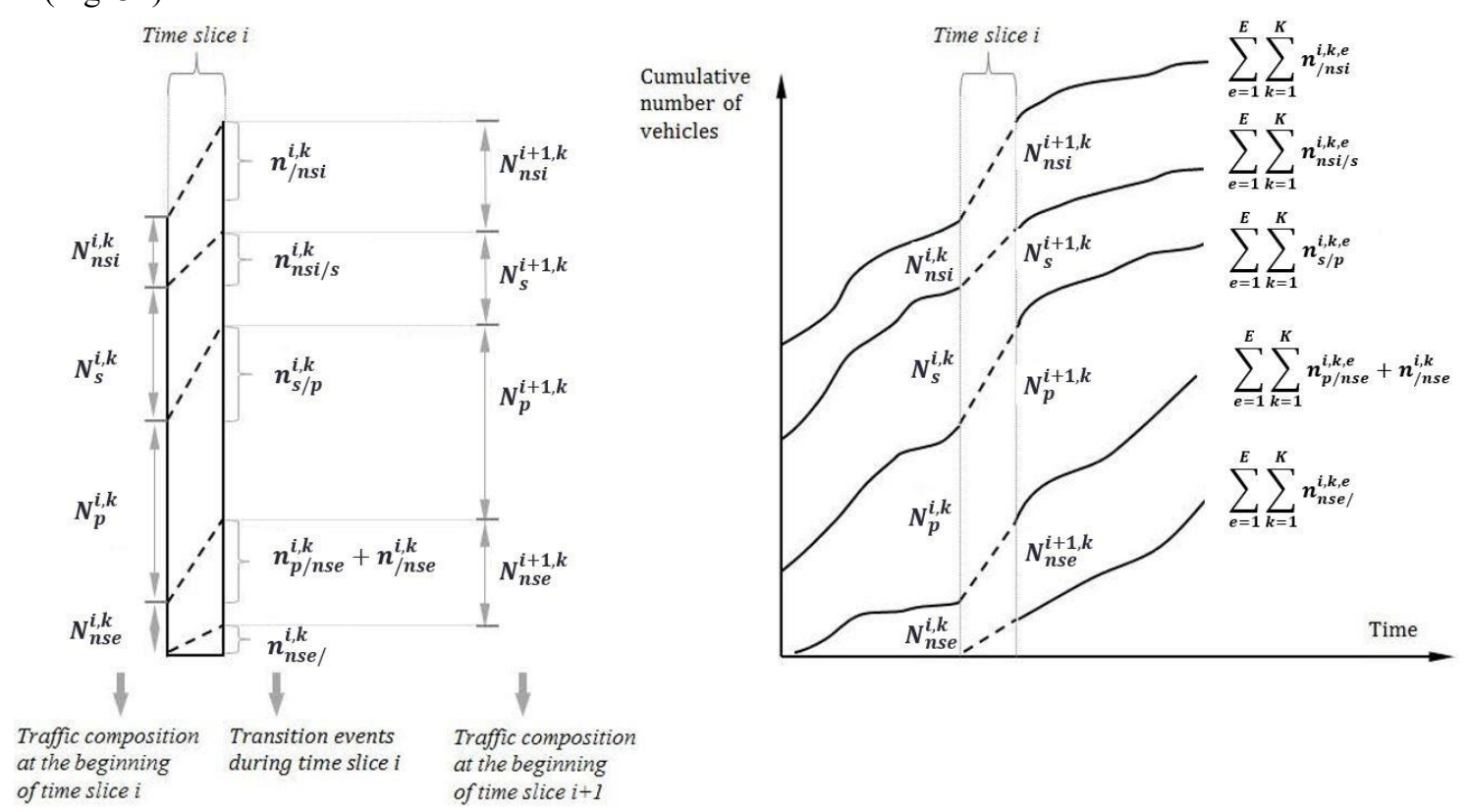

(a) Illustration of traffic composition and queuing diagram for cars entering the area.
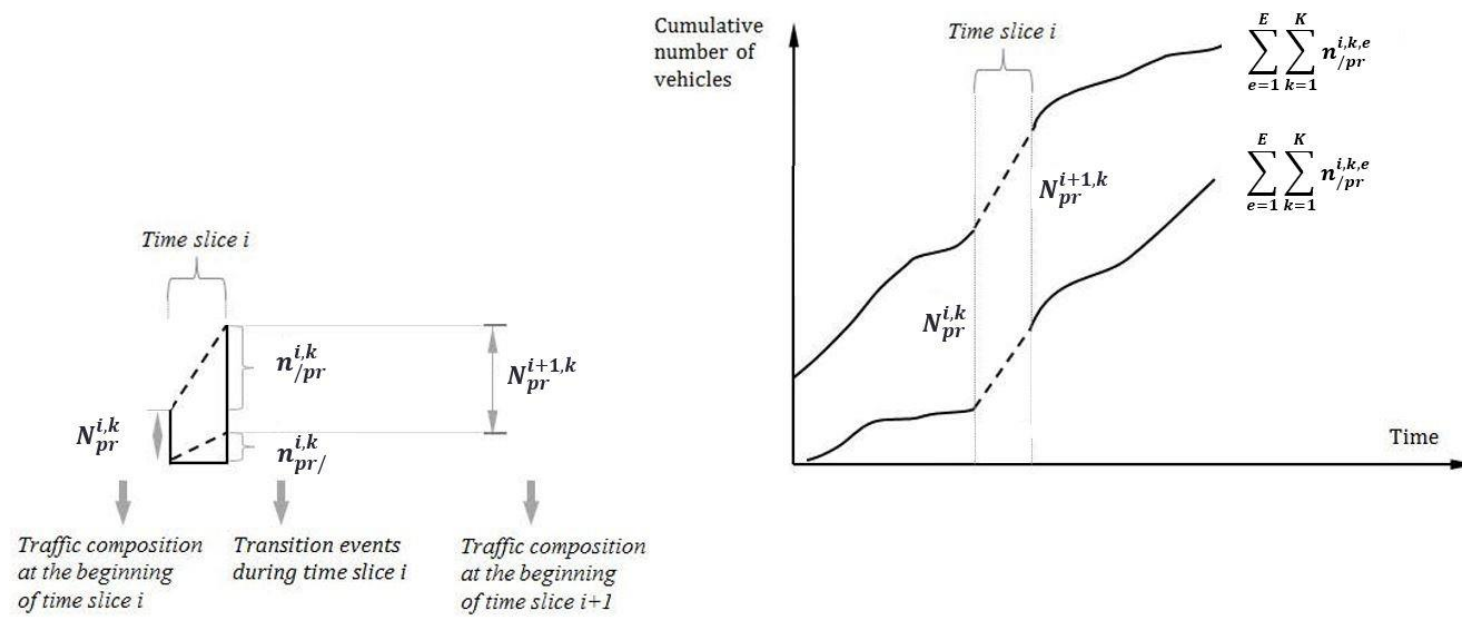

(b) Illustration of traffic composition and queuing diagram for cars switching to $\mathrm{P}+\mathrm{R}$.

Fig. 3. Traffic composition between consecutive time slices and queuing diagrams for cars entering the area or switching to $\mathrm{P}+\mathrm{R}$.

The average travel speed of cars, $v^{i}$, during time slice $i$ is formulated in Eq. (9a) based on the statistical model for the vehicle based 3D-MFD in [38]. It uses the free flow speed of cars, $v$, when traffic is not congested, and includes the marginal effects of each mode $\left(\vartheta_{c a r}\right.$ and $\vartheta_{P T}$ for cars and PT vehicles, respectively) on car speeds when traffic starts to be congested. The density of cars, $k_{\text {car }}^{i}$, is determined in Eq. (9b) based on the total number of cars on the road network (consisting of non-searching, $N_{n s e}^{i}+N_{n s i}^{i}$, and searching cars, $N_{s}^{i}$ ), and the network length, $L_{\text {lane }}$, in lane-km ([1ㅇ], [12],$[\underline{38}])$. The density of PT vehicles, $k_{P T}^{i}$, is computed in Eq. (9c) using the number of PT vehicles in the area divided by $L_{\text {lane }}$. The number of PT vehicles can be obtained as the cycle for one PT run, $2 \cdot A D D_{P T} / u^{i}$, divided by the average headway, $h$. 


$$
\begin{gathered}
v^{i}=v+\vartheta_{\text {car }} \cdot k_{\text {car }}^{i}+\vartheta_{P T} \cdot k_{P T}^{i} \\
k_{\text {car }}^{i}=\frac{N_{n s e}^{i}+N_{n s i}^{i}+N_{s}^{i}}{L_{\text {lane }}} \\
k_{P T}^{i}=\frac{2 \cdot A D D_{P T}}{u^{i} \cdot h \cdot L_{\text {lane }}}
\end{gathered}
$$

Below, we model each of the transition events. The total number of cars, $n_{/ n s}^{i, k}$, entering the network for user group $k \in K$ during time slice $i$ is considered as the known input demand to the model. Based on the proportion of throughtraffic (input to the model), $\beta^{i}$, and the choice of drivers entering the area by car or PT, $\delta_{c a r}^{i, k}$, the demand $n_{/ n s}^{i, k}$ is split based on three transition events (Fig. 4), Eq. (10a-c).

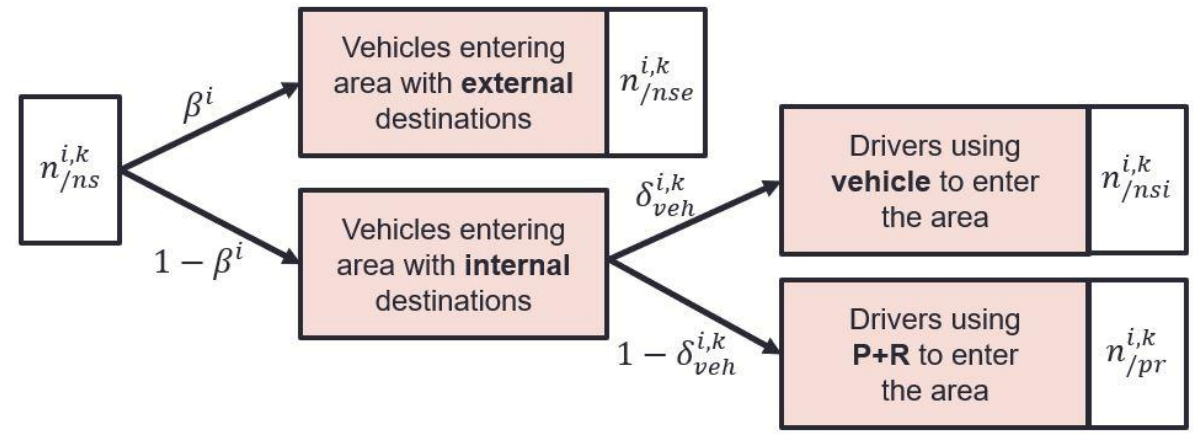

Fig. 4. The transition events with internal/external destinations using cars or $\mathrm{P}+\mathrm{R}$ to enter the area.

$$
\begin{aligned}
& n_{/ n s e}^{i, k}=\beta^{i} \cdot n_{/ n s}^{i, k} \\
& n_{/ n s i}^{i, k}=\left\{\begin{array}{c}
\left(1-\beta^{i}\right) \cdot n_{/ n s}^{i, k} \cdot \delta_{c a r}^{i, k}, \quad \text { if }\left(1-\beta^{i}\right) \cdot n_{/ n s}^{i, k} \cdot\left(1-\delta_{c a r}^{i, k}\right) \leq P^{i} \\
\left(1-\beta^{i}\right) \cdot n_{/ n s}^{i, k}-P^{i}, \quad \text { if }\left(1-\beta^{i}\right) \cdot n_{/ n s}^{i, k} \cdot\left(1-\delta_{c a r}^{i, k}\right)>P^{i}
\end{array}\right. \\
& n_{/ p r}^{i, k}=\left\{\begin{array}{cl}
\left(1-\beta^{i}\right) \cdot n_{/ n s}^{i, k} \cdot\left(1-\delta_{c a r}^{i, k}\right), & \text { if }\left(1-\beta^{i}\right) \cdot n_{/ n s}^{i, k} \cdot\left(1-\delta_{c a r}^{i, k}\right) \leq P^{i} \\
P^{i}, & \text { if }\left(1-\beta^{i}\right) \cdot n_{/ n s}^{i, k} \cdot\left(1-\delta_{c a r}^{i, k}\right)>P^{i}
\end{array}\right.
\end{aligned}
$$

In Eq. (10b-c) we differentiate between enough (i.e., $\left.\left(1-\beta^{i}\right) \cdot n_{/ n s}^{i, k} \cdot\left(1-\delta_{c a r}^{i, k}\right) \leq P^{i}\right)$ and not enough (i.e., $\left.\left(1-\beta^{i}\right) \cdot n_{/ n s}^{i, k} \cdot\left(1-\delta_{c a r}^{i, k}\right)>P^{i}\right)$ available parking spaces, $P^{i}$, at the $\mathrm{P}+\mathrm{R}$ facility. The proportion of through-traffic, $\beta^{i}$, is assumed to be independent of the individual user group $k \in K$. For cars entering the area we assume that they start searching for parking after driving a distance $l_{n s i / s}^{k}$, which is a function of the network size. $l_{n s i / s}^{k}$ can be fixed or follow any given probability density function. The number of cars starting to search for parking, $n_{n s i / s}^{i, k}$, for user group $k \in K$ are modelled in Eq. (11).

$$
n_{n s i / s}^{i, k}=\sum_{i^{\prime}=1}^{i-1} n_{/ n s i}^{i^{\prime}, k} \cdot \gamma_{n s i / s}^{i^{\prime}, k}
$$

where

$$
\gamma_{n s i / s}^{i^{\prime}, k}= \begin{cases}1, & \text { if } l_{n s i / s}^{k} \leq \sum_{j=i^{\prime}}^{j=i-1} d^{j} \text { and } \sum_{j=i^{\prime}}^{j=i-1} d^{j} \leq l_{n s i / s}^{k}+d^{i-1} \\ 0, & \text { otherwise }\end{cases}
$$


$\gamma_{n s i / s}^{i^{\prime}, k}$ in Eq. (11) indicates whether the cars $n_{/ n s i}^{i^{\prime}, k}$ have driven long enough, i.e., they cover a distance $l_{n s i / s}^{k}$, such that they start searching for parking in time slice $i$.

The number of cars finding, accessing and paying for parking, $n_{s / p}^{i, k}$, is modelled in Eq. (12) using the finding parking likelihood formulations from [10], [11] and [12]. It is a function of the number of available parking spaces $A^{i}$, the number of competing cars searching for parking $N_{s}^{i, k}$, and the distance an average searcher can drive in a single time slice in reference to the network length $v^{i} \cdot t / L$.

$$
n_{s / p}^{i, k}=\left\{\begin{array}{cc}
N_{s}^{i, k}\left[1-\left(1-\frac{v^{i} \cdot t}{L}\right)^{A^{i}}\right], & \text { if } t \in\left[0, \frac{L}{v^{i} \cdot N_{s}^{i, k}}\right] \\
A^{i}+\left[A^{i}-N_{s}^{i, k}+N_{s}^{i, k} \cdot\left(1-\frac{1}{N_{s}^{i, k}}\right)^{A^{i}}\right] \cdot\left(\frac{\left.\log \frac{N_{s}^{i, k}}{A^{i} \cdot \frac{v^{i} \cdot t}{L}}\right),}{\log A^{i}}\right) & \text { if } t \in\left[\frac{L}{\left.v^{i} \cdot N_{s}^{i, k}, \frac{L}{v^{i}} \cdot \frac{A^{i}}{N_{s}^{i, k}}\right]}, \text { if } A^{i} \leq N_{s}^{i, k}\right. \\
A^{i}, & \text { if } t \in\left[\frac{L}{v^{i}} \cdot \frac{A^{i}}{N_{s}^{i, k}}, \infty\right) \\
N_{s}^{i, k}\left[1-\left(1-\frac{v^{i} \cdot t}{L}\right)^{A^{i}}\right], & \text { if } t \in\left[0, \frac{L}{v^{i} \cdot N_{s}^{i, k}}\right] \\
N_{s}^{i, k}+N_{s}^{i, k} \cdot\left(1-\frac{1}{N_{s}^{i, k}}\right)^{A^{i}} \cdot\left(\frac{\log \frac{v^{i} \cdot t}{L}}{\log N_{s}^{i, k}}\right), & \text { if } t \in\left[\frac{L}{v^{i} \cdot N_{s}^{i, k}, \frac{L}{v^{i}}}\right]
\end{array}, \text { if } A^{i} \geq N_{s}^{i, k}\right.
$$

When $A^{i}<N_{s}^{i, k}$, the number of cars accessing parking is low as there are not enough available parking spaces for all drivers searching for parking. When $A^{i}>N_{s}^{i, k}$, the number of cars accessing parking can potentially be high depending on the drivers' distance driven in one time slice. The number of cars accessing parking might, however, be low in the latter case, if the length of a time slice, $t$, is very short. Notice that all drivers decide to access the first available parking space they find, as all parking spaces have the same price. More details on $n_{s / p}^{i, k}$ can be found in [10] with its simplified version in [11].

Once the cars depart from parking they move towards an external destination $\left(n_{p / n s e}^{i, k}\right.$ modelled in Eq. (13) for user group $k \in K$ during time slice $i$ ).

$$
n_{p / n s e}^{i, k}=\sum_{i^{\prime}=1}^{i-1} n_{s / p}^{i^{\prime}, k} \cdot \int_{\left(i-i^{\prime}\right) \cdot t}^{\left(i+1-i^{\prime}\right) \cdot t} f\left(t_{d, p}\right) d t_{d, p}
$$

$n_{p / n s e}^{i, k}$ is based on the distribution of parking durations $f\left(t_{d, p}\right)$ and on the number of cars having accessed parking spaces, $n_{s / p}^{i^{\prime}, k}$, in a former time slice $i^{\prime} \in[1, i-1]$. The likelihood that these cars depart from the parking spaces in time slice $i$ equals the probability of the parking duration being between $\left(i-i^{\prime}\right) \cdot t$ and $\left(i+1-i^{\prime}\right) \cdot t$, i.e., $\int_{\left(i-i^{\prime}\right) \cdot t}^{\left(i+1-i^{\prime}\right) \cdot t} f\left(t_{d, p}\right) d t_{d, p}$.

The transition event $n_{p r /}^{i, k}$ in Eq. (14) describes the number of cars departing from the $\mathrm{P}+\mathrm{R}$ spaces. It is modelled analogously to Eq. (13) depending on $n_{/ p r}^{i^{\prime}, k}$ and the distribution of $\mathrm{P}+\mathrm{R}$ durations $f\left(t_{d, p r}\right)$. 


$$
n_{p r /}^{i, k}=\sum_{i^{\prime}=1}^{i-1} n_{/ p r}^{i^{\prime}, k} \cdot \int_{\left(i-i^{\prime}\right) \cdot t}^{\left(i+1-i^{\prime}\right) \cdot t} f\left(t_{d, p r}\right) d t_{d, p r}
$$

After cars access or depart the parking spaces in the area and the $\mathrm{P}+\mathrm{R}$ facilities, the number of available parking spaces, $A^{i}$, and the number of available $\mathrm{P}+\mathrm{R}$ spaces, $P^{i}$, are updated in Eq. (15a-b). Neither $A^{i}$ nor $P^{i}$ can surpass the total number of existing parking/P+R spaces, i.e., $A^{i} \leq A$ and $P^{i} \leq P$ for any time slice $i$.

$$
\begin{aligned}
& A^{i}=A-N_{p}^{i} \\
& P^{i}=P-N_{p r}^{i}
\end{aligned}
$$

The cars heading towards external destinations, $n_{n s e /}^{i, k}$, leave the area after having driven a given distance $l_{/}^{k}$ or $l_{p /}^{k}$ depending on whether they have parked or not. The distances $l_{p /}^{k}$ and $l_{/}^{k}$ are - analogously to $l_{n s i / s}^{k}$ - considered as fixed or taken out of any given probability density function. They both depend on the network size and average trip lengths. $n_{n s e /}^{i, k}$ is modelled in Eq. (16) for user group $k \in K$ based on $n_{/ n s e}^{i^{\prime}, k}$ and $n_{p / n s e}^{i^{\prime}, k}$.

$$
n_{n s e /}^{i, k}=\sum_{i^{\prime}=1}^{i-1}\left(n_{/ n s e}^{i^{\prime}, k} \cdot \gamma_{/}^{i^{\prime}, k}+n_{p / n s e}^{i^{\prime}, k} \cdot \gamma_{p /}^{i^{\prime}, k}\right)
$$

where

$$
\begin{gathered}
\gamma_{/}^{i^{\prime}, k}= \begin{cases}1, & \text { if } l_{/}^{k} \leq \sum_{j=i^{\prime}}^{j=i-1} d^{j} \text { and } \sum_{j=i^{\prime}}^{j=i-1} d^{j} \leq l_{/}^{k}+d^{i-1} \\
0, & \text { otherwise }\end{cases} \\
\gamma_{p /}^{i^{\prime}, k}= \begin{cases}1, & \text { if } l_{p /}^{k} \leq \sum_{j=i^{\prime}}^{j=i-1} d^{j} \text { and } \sum_{j=i^{\prime}}^{j=i-1} d^{j} \leq l_{p /}^{k}+d^{i-1} \\
0, & \text { otherwise }\end{cases}
\end{gathered}
$$

$\gamma_{/}^{i^{\prime}, k}$ and $\gamma_{p /}^{i^{\prime}, k}$ in Eq. (16) indicate whether the cars $n_{/ n s e}^{i^{\prime}, k}$ and $n_{p / n s e}^{i^{\prime}, k}$ have driven $l_{/}^{k}$ and $l_{p /}^{k}$, respectively, to leave the area in time slice $i$.

\subsection{Traffic performance in the area}

The average searching time per car, $t_{s}$, in Eq. (17) reflects the traffic performance in the area and shows whether the network is congested or not. A high average searching time, for example, might occur due to a small number of available parking spaces in the area. This will lead to traffic congestion in the network.

$$
t_{s}=\frac{\sum_{i=1}^{T} \sum_{k=1}^{K} t \cdot N_{s}^{i, k}}{\sum_{i=1}^{T} \sum_{k=1}^{K} n_{s / p}^{i, k}}
$$

$t_{s}$ is determined by computing the total searching time for all user groups $k \in K$ in the network, $\sum_{i=1}^{T} \sum_{k=1}^{K} t \cdot N_{s}^{i, k}$, and dividing it by the total number of cars having searched for parking in the area, $\sum_{i=1}^{T} \sum_{k=1}^{K} n_{s / p}^{i, k}$, over the time horizon $T$. 


\subsection{Total revenue for the city}

Introducing parking and congestion pricing schemes are options for generating revenue $I_{\text {tot }}$ (Eq. (18)).

$$
I_{\text {tot }}=\underbrace{\sum_{i=1}^{T} \sum_{k=1}^{K}\left(n_{/ n s e}^{i, k}+n_{/ n s i}^{i, k}\right) \cdot p_{t}}_{\text {term } 1}+\underbrace{\sum_{i=1}^{T} \sum_{k=1}^{K} n_{p r /}^{i, k} \cdot\left(p_{p r}+p_{P T}\right)}_{\text {term } 2}+\underbrace{\sum_{i=1}^{T} \sum_{k=1}^{K} n_{p / n s e}^{i, k} \cdot p_{p} \cdot \overline{t_{d, p}}}_{\text {term } 3}
$$

Term 1 represents the revenue from the congestion toll for all $k \in K$ during all time slices $i$. Term 2 shows the revenue from the $\mathrm{P}+\mathrm{R}$ and the round-trip $\mathrm{PT}$ fees for all user groups $k \in K$ during all time slices $i$. Term 3 illustrates the revenue from parking in the area for all user groups $k \in K$ during all time slices $i$, depending on the average parking duration $\overline{t_{d, p}}$.

\section{Applications}

In this section, we illustrate the use of the proposed methodology by comparing different parking and congestion pricing scenarios for a central area with a high parking demand for public parking spaces within the city of Zurich, Switzerland. Our results help answering the question whether introducing congestion pricing is a necessity or implementing parking pricing strategies are sufficient to improve the area's traffic performance. Our case study uses real traffic and parking data obtained by [12] which is based on historical data collections and an agent-based model in MATSim ([54]). It was validated in [12] using the parking occupancy data over a working day based on a local monitoring system (PLS Zurich), and the cruising time based on survey results that were conducted during May 2016. The framework is implemented with the aid of a simple numerical solver such as Matlab.

\subsection{Case study of an area within the city of Zurich, Switzerland}

We concentrate on the study area in Fig. 5a around the shopping district Jelmoli $\left(0.28 \mathrm{~km}^{2}\right)$ in the city center of Zurich ([12]). This central area with many stores and offices mostly from the financial sector attracts $39 \%$ of all trips related to shopping, $35 \%$ related to leisure, and $26 \%$ related to business activities (survey from May 2016 ([12])). The total length of all roads is $L=7.7 \mathrm{~km}$, and $b=76 \mathrm{~m}$. As most of the streets have two lanes (either one lane per direction or two lanes in a one-way street), the total network length is $L_{\text {lane }}=15.4$ lane-km.

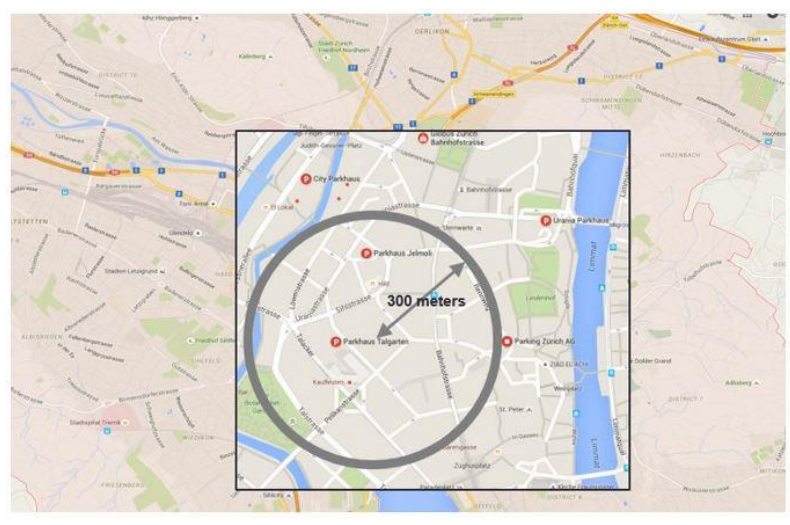

(a) Case study area in the city center of Zurich.

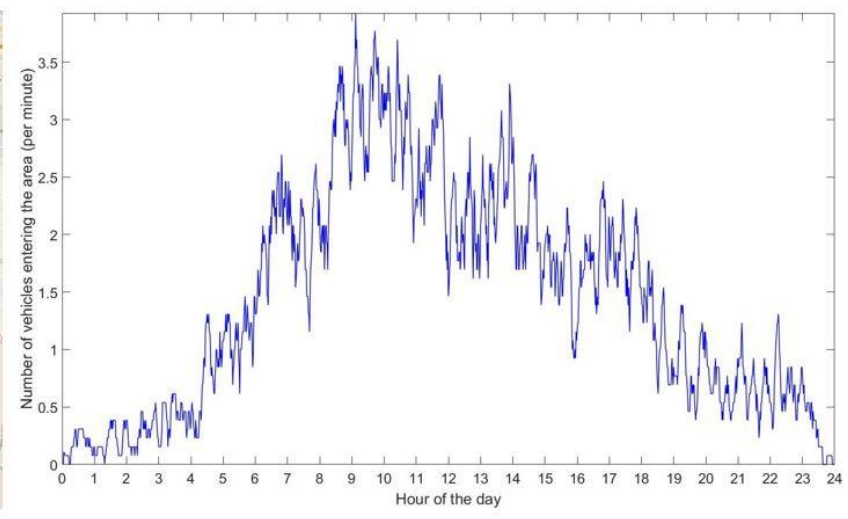

(b) Number of cars entering the area over one day.

Fig. 5. Case study area and parking demand per minute computed as a moving average over 10 min (Source: [12]).

There are 539 public parking spaces in the area. As the policy of removing on-street parking spaces without necessarily downsizing the overall parking supply has been evaluated in the inner-city of Zurich since the 1990's (Zurich parking 
supply cap system in [20]), we assume that 200 on-street parking spaces can be moved out of our network and turned into $\mathrm{P}+\mathrm{R}$ spaces, i.e., $P=200$. The remaining $A=339$ parking spaces stay in the area. It is assumed that the recovered road space while removing on-street parking spaces in the inner-city area has no influence on the traffic flow, and can be used for other activities (e.g., to create pedestrian zones or bicycle lanes). The $\mathrm{P}+\mathrm{R}$ fee outside the area is a fixed lump-sum for parking up to $T=1440 \mathrm{~min}$. The average $\mathrm{P}+\mathrm{Rail}$ fee around the city of Zurich including the round-trip PT fee paid to enter the area from the $\mathrm{P}+\mathrm{R}$ facility by PT equals $p_{p r}+p_{P T}=10$ CHF ([47], [52]). Both $\mathrm{P}+\mathrm{R}$ outside and parking spaces inside the area have no parking time limit, i.e., drivers can park there for the whole time horizon of 24 hours. The working day is divided into time slices of $1 \mathrm{~min}$, i.e., $t=1 \mathrm{~min}$. The traffic properties (i.e., $v=27.93 \mathrm{~km} / \mathrm{h}$ ) and model parameters $\vartheta_{c a r}, \vartheta_{P T}, \mu_{c a r}$, and $\mu_{P T}$ are based on the 3D-MFD of the

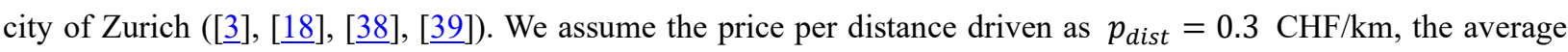
distance driven from the $\mathrm{P}+\mathrm{R}$ facility to the area as $l_{P T}=5 b=380 \mathrm{~m}$, and the walking speed as $w=5 \mathrm{~km} / \mathrm{h}([7])$. The average headway of PT lines from the P+R facility to the PT stops is $h=7.5 \mathrm{~min}$ and the total number of PT stops in the area is $S=2$. Here we use bus line 31 and tram lines 2, 7, 9, 10 and 13 in Zurich as a reference for $h$ and $S([14])$.

The parking demand in Fig. 5b, the distribution of parking durations in Fig. 6, and the initial conditions are based on an agent-based model in MATSim, which is in turn, based on previous measurements. This has been validated for the city of Zurich in [54]. The parking demand (Fig. 5b) of 2687 trips is split into $K=4$ different user groups (892/ 956/ 838/ 956 trips) associated with different VOTs $\left(V O T^{1}=29.9 \mathrm{CHF} / \mathrm{h} ; V_{O T}{ }^{2}=25.4 \mathrm{CHF} / \mathrm{h} ; V^{2} T^{3}=\right.$ 25.8 $\mathrm{CHF} / \mathrm{h} ; V T^{4}=17.2 \mathrm{CHF} / \mathrm{h}$ ) which are based on the estimated VOT mean values for car journeys in Switzerland ([] $]$ ). 23\% (618 trips) of the daily traffic (i.e., $\beta^{i}=0.23, \forall i$ ) does not search for parking (throughtraffic), and the remaining 77\% (2069 trips) searches for parking. The parking durations (Fig. 6) are described by a probability density function following a gamma distribution with a shape parameter of 1.6 and a scale parameter of 142 . The average parking duration is $227 \mathrm{~min}$ ([12]). We assume that parking durations at $\mathrm{P}+\mathrm{R}$ spaces are longer than parking durations in the area as they additionally account for the drivers' PT time, i.e., we add the average roundtrip PT waiting and travel time to the parking durations in the area in order to determine the parking durations at $\mathrm{P}+\mathrm{R}$ spaces.

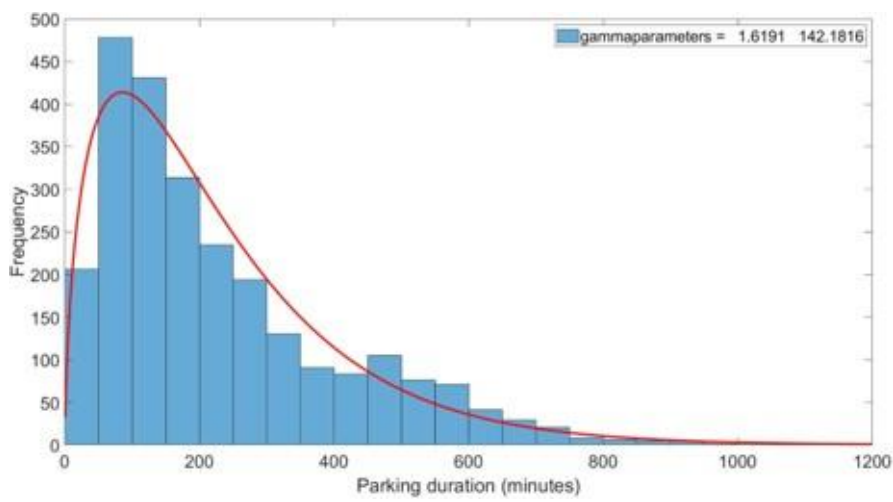

Fig. 6. Distribution of parking durations.

The initial conditions include $N_{p}^{0}=113$ cars already parked in the area and $N_{p r}^{0}=70$ cars parked at P+R facilities at the beginning of the working day. All further initial conditions are considered as zero, i.e., $N_{n s e}^{0}=N_{n s i}^{0}=N_{s}^{0}=0$. The travel distances $l_{n s i / s}^{k}, l_{/}^{k}$ and $l_{p /}^{k}$ follow a uniform distribution between 0.1 and $0.7 \mathrm{~km}$ for all $k \in$ $\{1, \ldots, 4\}$. 


\subsection{Impact of parking and congestion pricing}

This section focuses on the traffic impacts from different parking and congestion pricing scenarios. First, we explain the status quo in the city of Zurich (scenario (a) in Table 4). Currently, there are no $\mathrm{P}+\mathrm{R}$ facilities (besides the ones at rail stations around Zurich) and there is no congestion toll around this case study area. The hourly parking pricing fee of $2.25 \mathrm{CHF}$ approximates the average value in the city center of Zurich ([12], [ㅌ5]). We compare this reference scenario to the assumed scenarios (b)-(e) in Table 4 in terms of traffic performance (average time spent) in the network and total revenue for the city.

Table 4. Scenarios and their pricing strategy.

\begin{tabular}{|c|c|}
\hline Scenarios & Pricing strategy \\
\hline $\begin{array}{l}\text { Scenario (a): } \\
\text { Reference scenario: } \\
\text { No P+R facilities }\end{array}$ & $\begin{array}{l}\text { No P+R facilities, no PT and no congestion toll are considered. Hourly parking pricing is set to } 2.25 \mathrm{CHF} \text { in the area } \\
\text { for all time slices. }\end{array}$ \\
\hline $\begin{array}{l}\text { Scenario (b): Free } \mathrm{P}+\mathrm{R} \\
\text { and free PT }\end{array}$ & $\begin{array}{l}\mathrm{P}+\mathrm{R} \text { facilities and } \mathrm{PT} \text { are introduced, i.e., } 200 \text { on-street parking spaces are moved outside the area as } \mathrm{P}+\mathrm{R} \text { spaces. } \\
\mathrm{P}+\mathrm{R} \text { and } \mathrm{PT} \text { fees are set to } 0 \mathrm{CHF} \text {. No congestion toll is considered. Hourly parking pricing is set to } 2.25 \mathrm{CHF} \text { in the } \\
\text { area for all time slices. }\end{array}$ \\
\hline $\begin{array}{l}\text { Scenario (c): Parking } \\
\text { pricing (policy } 1)\end{array}$ & $\begin{array}{l}\mathrm{P}+\mathrm{R} \text { facilities and PT are introduced, i.e., } 200 \text { on-street parking spaces are moved outside the area as P+R spaces. } \\
\mathrm{P}+\mathrm{R} \text { fees including round-trip PT fees are set to } 10 \mathrm{CHF} \text { for up to } 24 \text { hours. Congestion pricing is set to } 0 \mathrm{CHF} \text { in the } \\
\text { area for all time slices. Hourly parking pricing is doubled and set to } 4.5 \mathrm{CHF} \text { in the area for all time slices. }\end{array}$ \\
\hline $\begin{array}{l}\text { Scenario }(\mathrm{d}) \text { : } \\
\text { Congestion pricing } \\
\text { (policy 2) }\end{array}$ & $\begin{array}{l}\mathrm{P}+\mathrm{R} \text { facilities and PT are introduced, i.e., } 200 \text { on-street parking spaces are moved outside the area as } \mathrm{P}+\mathrm{R} \text { spaces. } \\
\mathrm{P}+\mathrm{R} \text { fees including round-trip PT fees are set to } 10 \mathrm{CHF} \text { for up to } 24 \text { hours. Congestion pricing is set to } 12 \mathrm{CHF} \text { in the } \\
\text { area for all time slices. Hourly parking pricing is set to } 0 \mathrm{CHF} \text { in the area for all time slices. }\end{array}$ \\
\hline $\begin{array}{l}\text { Scenario (e): Parking } \\
\text { and congestion pricing } \\
\text { (combined policies } 1 \\
\text { and } 2 \text { ) }\end{array}$ & $\begin{array}{l}\mathrm{P}+\mathrm{R} \text { facilities and } \mathrm{PT} \text { are introduced, i.e., } 200 \text { on-street parking spaces are moved outside the area as } \mathrm{P}+\mathrm{R} \text { spaces. } \\
\mathrm{P}+\mathrm{R} \text { fees including round-trip PT fees are set to } 10 \mathrm{CHF} \text { for up to } 24 \text { hours. Congestion pricing is set to } 12 \mathrm{CHF} \text { in the } \\
\text { area for all time slices. Hourly parking pricing is set to } 4.5 \mathrm{CHF} \text { in the area for all time slices. }\end{array}$ \\
\hline
\end{tabular}

Table 5 shows the results for the traffic criteria including traffic performance (i.e., average/total searching and nonsearching time), congestion (i.e., average/total delay, and queue reflected as the average number of cars searching for parking), traffic state volumes, and total revenue for the different scenarios in Table 4 . The delay is determined as the difference between the actual and ideal travel time in the area. The latter is the time the cars spend under free-flow conditions in the network. Recall that the parking and $\mathrm{P}+\mathrm{R}$ revenues come only from the cars that park in the area or at the $\mathrm{P}+\mathrm{R}$ facilities, but the revenue from congestion pricing includes every single car that comes into the network, whether they park or not.

The reference scenario (a) requires the longest average/total searching and non-searching time, and the longest average/total delay compared to all other scenarios since there are no $\mathrm{P}+\mathrm{R}$ facilities outside the area, i.e., all assumed scenarios (b)-(e) improve the traffic performance in the area. However, different policies lead to different results (Table 5). Scenario (b) analyzes the policy of moving 200 on-street parking spaces outside the area as free $P+R$ spaces with free PT while the hourly parking pricing in the area is kept at $2.25 \mathrm{CHF}$. The results show a lower boundary for the average time values in Table 5, i.e., how much we can reduce the average searching and non-searching time by encouraging drivers to use the available free $\mathrm{P}+\mathrm{R}$ facilities $(32.1 \%$ and $43.8 \%$, respectively). The average delay decreases significantly by $56 \%$ as on average 164.2 cars decide to use $\mathrm{P}+\mathrm{R}$ instead of parking in the area. Scenario (c) considers the parking pricing policy (policy 1 in section 2) with an increased hourly parking fee of $4.5 \mathrm{CHF}$ in the area. The $\mathrm{P}+\mathrm{R}$ fees including round-trip PT fees are set to $10 \mathrm{CHF}$ for 24 hours. This decreases the average searching time by $27.2 \%$ compared to scenario (a) as on average 141 drivers decide to use $\mathrm{P}+\mathrm{R}$ instead of entering the area by car. In addition, the average non-searching time and the average delay significantly decrease by $37 \%$ and $46.7 \%$, respectively. The $\mathrm{P}+\mathrm{R}$ and $\mathrm{PT}$ fees, as well as the higher parking fees lead to an increased revenue of 


\section{8,999 CHF.}

Table 5. Comparison of different policies in terms of traffic performance, congestion, traffic state volumes, and total revenue for the city. Value within parenthesis represents the percentage change with respect to the reference scenario.

\begin{tabular}{|c|c|c|c|c|c|}
\hline Scenarios & $\begin{array}{l}\text { Scenario (a): } \\
\text { Reference } \\
\text { scenario: No } \\
\text { P+R facilities }\end{array}$ & $\begin{array}{l}\text { Scenario }(b): \\
\text { Free P+R and } \\
\quad \text { free PT }\end{array}$ & $\begin{array}{c}\text { Scenario (c): } \\
\text { Parking pricing } \\
\text { (policy 1) }\end{array}$ & $\begin{array}{l}\text { Scenario }(d): \\
\text { Congestion } \\
\text { pricing } \\
\text { (policy 2) }\end{array}$ & $\begin{array}{c}\text { Scenario (e): } \\
\text { Parking and } \\
\text { congestion pricing } \\
\text { (combined policies } \\
1 \text { and 2) }\end{array}$ \\
\hline $\begin{array}{l}\text { Average time for cars searching } \\
\text { for parking }(\mathrm{min} / \mathrm{veh})\end{array}$ & 2.68 & $\begin{array}{l}1.82 \\
(-32.1 \%)\end{array}$ & $\begin{array}{l}1.95 \\
(-27.2 \%)\end{array}$ & $\begin{array}{l}2.09 \\
(-22 \%)\end{array}$ & $\begin{array}{l}1.89 \\
(-29.5 \%)\end{array}$ \\
\hline $\begin{array}{l}\text { Total time for cars searching for } \\
\text { parking (min) }\end{array}$ & 6,036 & $\begin{array}{l}4,099 \\
(-32.1 \%)\end{array}$ & $\begin{array}{l}4,395 \\
(-27.2 \%)\end{array}$ & $\begin{array}{l}4,710 \\
(-22 \%)\end{array}$ & $\begin{array}{l}4,244 \\
(-29.7 \%)\end{array}$ \\
\hline $\begin{array}{l}\text { Average travel time for cars non- } \\
\text { searching ( } \mathrm{min} / \mathrm{veh})\end{array}$ & 2.97 & $\begin{array}{l}1.67 \\
(-43.8 \%)\end{array}$ & $\begin{array}{l}1.87 \\
(-37 \%)\end{array}$ & $\begin{array}{l}1.97 \\
(-33.7 \%)\end{array}$ & $\begin{array}{l}1.78 \\
(-40.1 \%)\end{array}$ \\
\hline $\begin{array}{l}\text { Total travel time for cars non- } \\
\text { searching (min) }\end{array}$ & 6,679 & $\begin{array}{l}3,751 \\
(-43.8 \%)\end{array}$ & $\begin{array}{l}4,205 \\
(-37 \%)\end{array}$ & $\begin{array}{l}4,434 \\
(-33.6 \%)\end{array}$ & $\begin{array}{l}4,006 \\
(-40 \%)\end{array}$ \\
\hline Average delay (min) & 2.91 & $\begin{array}{l}1.28 \\
(-56 \%)\end{array}$ & $\begin{array}{l}1.55 \\
(-46.7 \%)\end{array}$ & $\begin{array}{l}1.75 \\
(-39.9 \%)\end{array}$ & $\begin{array}{l}1.43 \\
(-50.9 \%)\end{array}$ \\
\hline Total delay (min) & 8,628 & $\begin{array}{l}3,764 \\
(-56.4 \%)\end{array}$ & $\begin{array}{l}4,513 \\
(-47.7 \%)\end{array}$ & $\begin{array}{l}5,057 \\
(-41.4 \%)\end{array}$ & $\begin{array}{l}4,164 \\
(-51.7 \%)\end{array}$ \\
\hline $\begin{array}{l}\text { Average number of cars non- } \\
\text { searching (external destination) } \\
\text { (veh/min) }\end{array}$ & 2.62 & $\begin{array}{l}1.64 \\
(-37.4 \%)\end{array}$ & $\begin{array}{l}1.77 \\
(-32.4 \%)\end{array}$ & $\begin{array}{l}1.84 \\
(-29.8 \%)\end{array}$ & $\begin{array}{l}1.71 \\
(-34.7 \%)\end{array}$ \\
\hline $\begin{array}{l}\text { Average number of cars non- } \\
\text { searching (internal destination) } \\
\text { (veh/min) }\end{array}$ & 2.02 & $\begin{array}{l}0.97 \\
(-52 \%)\end{array}$ & $\begin{array}{l}1.15 \\
(-43.1 \%)\end{array}$ & $\begin{array}{l}1.24 \\
(-38.6 \%)\end{array}$ & $\begin{array}{l}1.07 \\
(-47 \%)\end{array}$ \\
\hline $\begin{array}{l}\text { Average number of cars } \\
\text { searching for parking (veh/min) }\end{array}$ & 4.19 & $\begin{array}{l}2.85 \\
(-32 \%)\end{array}$ & $\begin{array}{l}3.05 \\
(-27.2 \%)\end{array}$ & $\begin{array}{l}3.27 \\
(-22 \%)\end{array}$ & $\begin{array}{l}2.95 \\
(-29.6 \%)\end{array}$ \\
\hline $\begin{array}{l}\text { Average number of cars parking } \\
\text { in the area (veh/min) }\end{array}$ & 337.99 & $\begin{array}{l}172.27 \\
(-49 \%)\end{array}$ & $\begin{array}{l}195.47 \\
(-42.2 \%)\end{array}$ & $\begin{array}{l}207.85 \\
(-38.5 \%)\end{array}$ & $\begin{array}{l}185.1 \\
(-45.2 \%)\end{array}$ \\
\hline $\begin{array}{l}\text { Average number of cars using } \\
\mathrm{P}+\mathrm{R} \text { (veh/min) }\end{array}$ & 0 & 164.16 & 141.05 & 128.76 & 151.36 \\
\hline $\begin{array}{l}\text { Revenue from } \mathrm{P}+\mathrm{R} \text { facilities and } \\
\text { PT }(\mathrm{CHF})\end{array}$ & 0 & 0 & 8,886 & 7,989 & 9,693 \\
\hline $\begin{array}{l}\text { Revenue from congestion tolls } \\
(\mathrm{CHF})\end{array}$ & 0 & 0 & 0 & 22,657 & 20,612 \\
\hline $\begin{array}{l}\text { Revenue from parking pricing } \\
(\mathrm{CHF})\end{array}$ & 17,628 & 8,438 & 20,113 & 0 & 18,738 \\
\hline $\begin{array}{l}\text { Total revenue created } \\
\text { by } \mathrm{P}+\mathrm{R} \text { facilities, } \mathrm{PT} \text {, parking } \\
\text { pricing and congestion tolls } \\
(\mathrm{CHF})\end{array}$ & 17,628 & $\begin{array}{l}8,438 \\
(-52.1 \%)\end{array}$ & $\begin{array}{l}28,999 \\
(+64.5 \%)\end{array}$ & $\begin{array}{l}30,646 \\
(+73.9 \%)\end{array}$ & $\begin{array}{l}49,043 \\
(+178.2 \%)\end{array}$ \\
\hline
\end{tabular}

Scenario (d) describes the congestion pricing policy (policy 2 in section 2) with a congestion toll set to 12 CHF (comparable to London, U.K. ([51])) and free parking in the area for all time slices. It considers the same P+R conditions as in scenario (c). As the congestion toll (scenario (d)) is cheaper than the parking fee for the drivers' expected parking durations (scenario (c)), more drivers would like to enter the area by car. This leads to a higher searching and non-searching time, and a higher delay/queue in scenario (d) compared to scenario (c). When comparing both scenarios (policy 1 and 2), then introducing parking pricing not only leads to better traffic performance and congestion results, but also to a similar increase in revenue for the city council. In addition, parking pricing (policy 1) might be the preferred scenario as it is not only easier to implement, but also socially and politically more accepted than congestion pricing. The significant traffic performance improvements of policy 1 compared to scenario (a) also 
support a decision towards a parking pricing implementation. Notice that this is in part possible because in this case the majority of the traffic coming into the area is searching for parking (i.e., $1-\beta^{i}=0.77$ for all time slices $i$ ). Even if the total revenue in scenario (c) is slightly less than in scenario (d), we would like to highlight that this revenue is mainly dependent on the hourly parking fee rate. It can increase with a higher parking fee, but this in turn, might raise social acceptability issues in the city. Scenario (e) combines the parking and parking pricing policies 1 and 2 . The traffic performance improves compared to both scenarios (c) and (d) and it comes close to the best performance in scenario (b). The resulting daily revenue of 49,043 CHF is the highest compared to all other scenarios in Table 5 . Nevertheless, this high revenue comes along with all the negative aspects of introducing congestion pricing to an area.

In the following, we present more details about policy 1 (scenario (c)) in comparison with the status quo (reference scenario (a)). Most drivers are searching for parking between the 11th and 16th hour due to a low number of available parking spaces, i.e., there are more searching cars in the area than available parking spaces (Fig. 7b, scenario (c)). $66 \%$ of the cruising-for-parking traffic occurs in this time period due to shopping, leisure and/or business activities ([12]). This leads to a high average searching time (Fig. 7a). Applying policy 1 reduces the average searching time during the peaks at the 12 th and the 14 th hour by more than 2.5 min compared to the reference scenario (a). The highest peak happens at the 12th hour, when 28 cars are cruising for parking while at the same time only 2 parking spaces are available (Fig. 7b). The parking system in the area remains full between the 11th and the 15th hour. After the 15 th hour, parking spaces become available again as cars gradually leave the area. Note that the number of available parking spaces before the 10th and after the 16th hour exceeds 30 and is not visible in Fig. $7 \mathrm{~b}$.

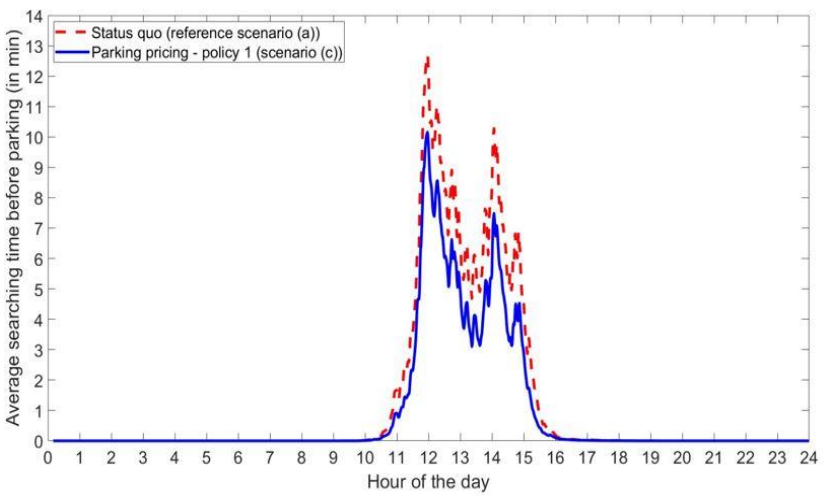

(a) Average searching time before parking.



(b) Searching cars vs. available parking spaces (scenario (c)).

Fig. 7. Cars searching for an available parking space in the area over a typical working day.

\subsection{Sensitivity analysis}

In this section, we conduct a sensitivity analysis for policy 1 (scenario (c) in section 4.2) to quantitatively evaluate the effects of some influencing factors (Table 6) on the traffic and parking model outputs.

Table 6. Influencing factors and their reference values for this sensitivity analysis.

\begin{tabular}{ll}
\hline Influencing factors & Reference values \\
\hline VOTs, $V O T^{k}$, for all user groups $k \in K$ & $V O T^{1}=29.9 \mathrm{CHF} / \mathrm{h} ; V O T^{2}=25.4 \mathrm{CHF} / \mathrm{h} ;$ \\
& $V O T^{3}=25.8 \mathrm{CHF} / \mathrm{h} ; V O T^{4}=17.2 \mathrm{CHF} / \mathrm{h}$ \\
\hline Total number of existing parking spaces inside the area, $A$ & $A=339$ \\
\hline Total number of existing P+R spaces outside the area, $P$ & $P=200$ \\
\hline P+R fee, $p_{p r}$, and round-trip PT fee, $p_{P T}$ & $p_{p r}+p_{P T}=10 \mathrm{CHF}$ \\
\hline
\end{tabular}

Fig. 8 shows how the average searching time (Fig. 8a) and the total revenue (Fig. 8b) change as a function of each of these four factors (each shown with a different line). 


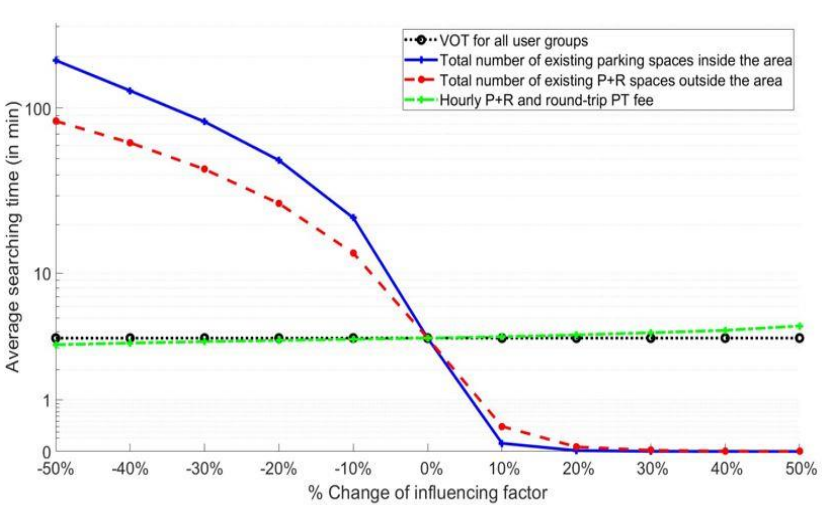

(a) Sensitivity analysis of the average searching time (log scale).

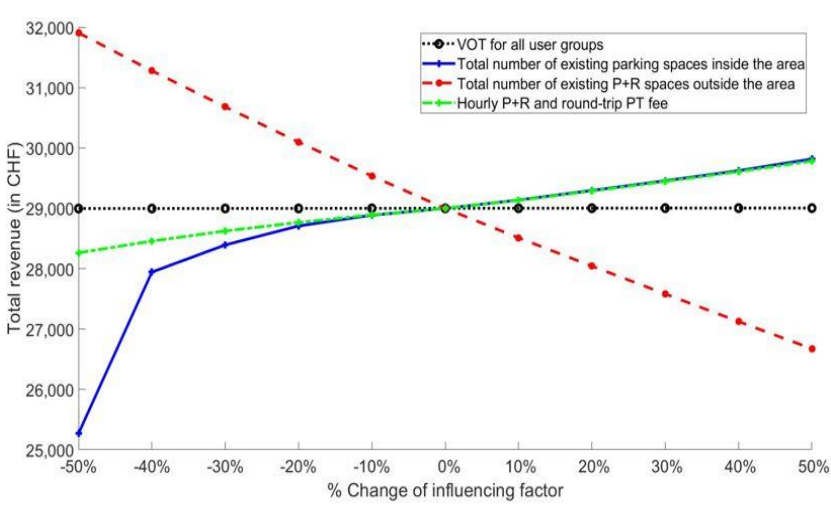

(b) Sensitivity analysis of the total revenue.

Fig. 8. Sensitivity analysis of the traffic performance over the peak period between the 10 th and the 16 th hour of one working day and the total revenue over one full working day (for an independent $A$ and $P$ ).

Fig. 8a shows that $V O T^{k}$ for all $k \in K$, and $p_{p r}+p_{P T}$ have no influence on the average searching time over the peak period between the 10th and the 16th hour of one working day. However, there is a clear dependency between the number of parking and $\mathrm{P}+\mathrm{R}$ spaces, $A$ and $P$, and the traffic performance. Decreasing $A$ or $P$ significantly increases the average time searching for parking. It decreases faster for $A$, as our case study considers $69.5 \%$ more parking spaces in the area than $\mathrm{P}+\mathrm{R}$ spaces outside the area. On the other hand, increasing $A$ or $P$ leads to a small decrease in the average searching time. This indicates an asymmetric relation between changes to $A$ or $P$ and the resulting changes in searching times.

Fig. $8 \mathrm{~b}$ illustrates the sensitivity analysis of the total revenue from one working day. The $V O T^{k}$ for all $k \in K, p_{p r}$ and $p_{P T}$ have only a marginal influence on the total revenue collected - compared to both $A$ and $P$. Interestingly, the revenue increases when the number of $\mathrm{P}+\mathrm{R}$ spaces, $P$, decreases and it decreases when $P$ increases. In case of fewer $\mathrm{P}+\mathrm{R}$ spaces, more drivers have to decide for a parking space in the area. The higher hourly parking fees in the area in comparison to $\mathrm{P}+\mathrm{R}$ explain this gain in revenue. Additionally, less parking spaces, $A$, inside the area lead to a decline in revenue, and a higher $A$ lead to a small raise in revenue.

Evidently, changes to $A$ and $P$ have a significant impact on the traffic performance and the total revenue for the city. In Fig. 8 we treated both $A$ and $P$ independently from each other. However, Zurich introduced a parking supply cap system in the inner-city in 1990 ([20] $)$ : for every newly introduced parking space an existing on-street parking space must be removed such that the parking supply is kept the same ([36]). Thus, we assume now $A$ and $P$ are dependent on each other, i.e., $A+P=539$, and conduct a sensitivity analysis of the average searching time over the peak period between the 10th and the 16th hour of one working day and the total revenue from one full working day (Fig. 9).

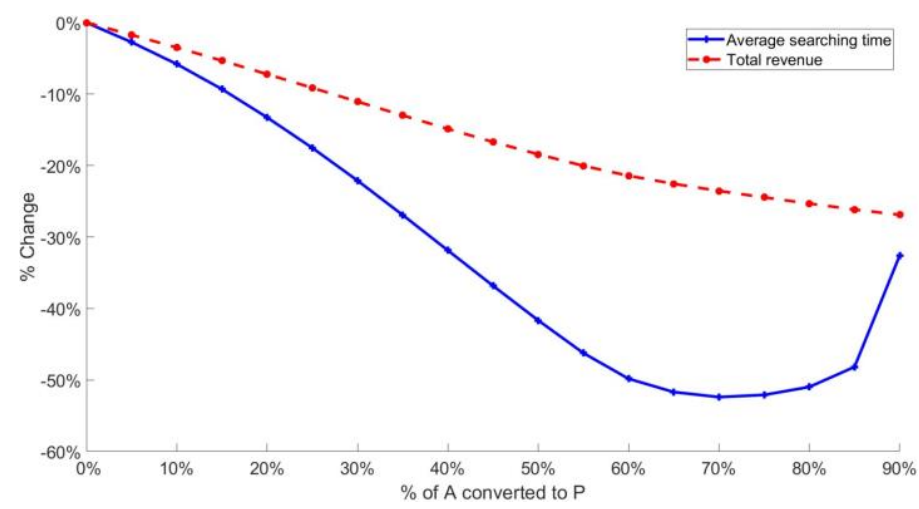

Fig. 9. Sensitivity analysis of the traffic performance over the peak period between the 10th and the 16th hour of one working day and the total revenue over one full working day (for a dependent $A$ and $P$, i.e., $A+P=539$ ). 
Fig. 9 shows that converting up to $80 \%$ of the parking spaces inside the area, $A$, into $\mathrm{P}+\mathrm{R}$ spaces, $P$, leads to less drivers entering the network and significantly lowers the searching times. Interestingly, this reflects an opposite relation between reductions of $A$ and the resulting changes in searching times than that shown in Fig. 8a. The reason is the increases in $\mathrm{P}+\mathrm{R}$ facilities, which create opportunities for people to park outside the area and avoid the whole searching for parking phenomenon. Notice, also, that the relation between the conversion rate and the reduction in searching times is not monotonically decreasing. Beyond a certain point, $\sim 80 \%$, the average searching time in the area increases with further conversions. In other words, we can always expect that some people would prefer to park inside the area, and reducing the parking supply too much will just increase the searching times. The higher $\mathrm{P}+\mathrm{R}$ capacity affects the drivers' decision between entering the area by car or switching to $\mathrm{P}+\mathrm{R}$ instead. This leads to more drivers switching to $\mathrm{P}+\mathrm{R}$, such that the $\mathrm{P}+\mathrm{R}$ occupancy increases faster. The very low availability of $\mathrm{P}+\mathrm{R}$ spaces leads, in turn, to some drivers entering the area by car. Due to the low capacity of parking spaces in the area (caused by a high conversion rate), the drivers face a longer time searching for an available parking space. From the revenue perspective, the relation is quite intuitive. Less parking spaces inside the area lead to a decline in revenue. Such a decline is lower than the one shown in Fig. $8 \mathrm{~b}$ as it is partially compensated by an increase in the revenues from $\mathrm{P}+\mathrm{R}$. In [9], an in-depth sensitivity analysis ([2] $]$ ) was conducted to analyze the effects of $l_{n s i / s}^{k}, l_{/}^{k}$ and $l_{p /}^{k}$ on the model outputs. The outcomes show that the model results are not sensitive to these distance variables as long as they are

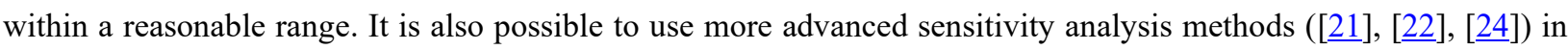
future research to have a deeper understanding of the relations between the different influencing factors.

\subsection{Trade-offs between parking fee and congestion toll}

When introducing congestion pricing, it is often a challenge for city councils to find the best relation between parking pricing and the congestion toll. Since all variables in our framework are based on average values and not on random values, every simulation run returns the same results as long as the input variables to the model are not changed. This means that the number of cars of all transition events and the number of available parking spaces on the network are deterministic at the beginning of each time slice. We run a simulation-based search algorithm based on multiple simulation runs to understand the effects of all possible relations $\frac{p_{t}}{p_{p}}$ on the average searching time (Fig. 10a) and revenue (Fig. 10b).

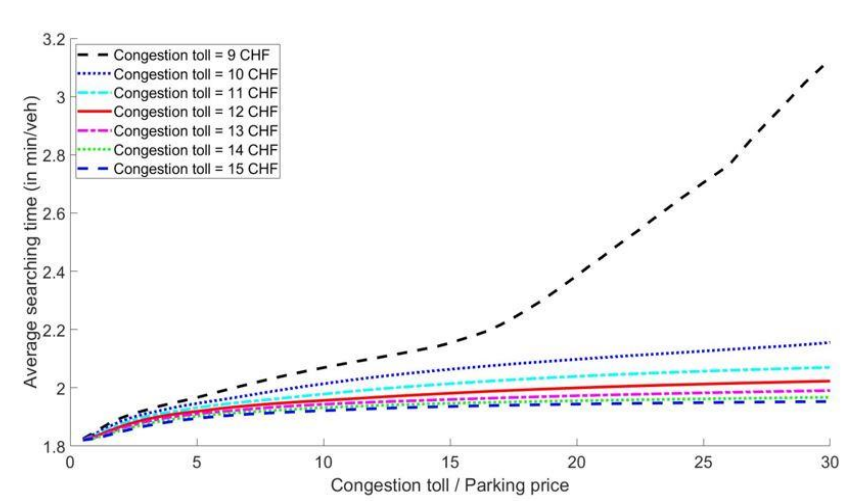

(a) Average searching time.

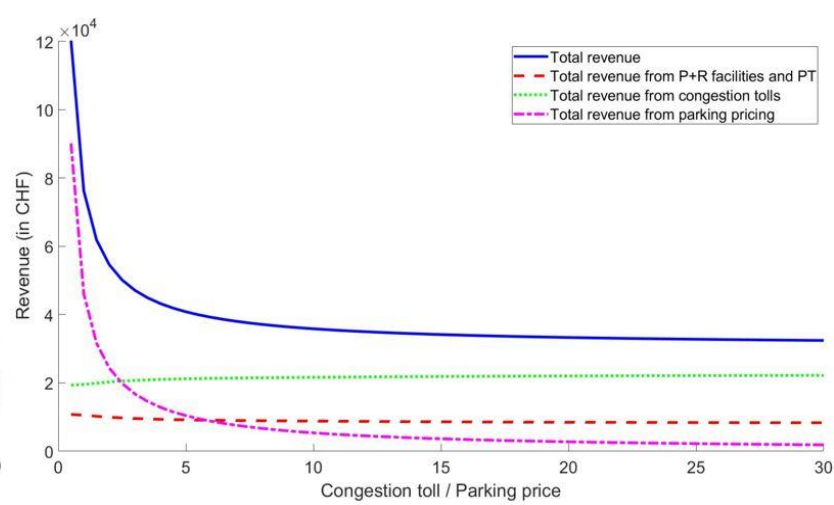

(b) Revenue based on congestion toll $=12 \mathrm{CHF}$.

Fig. 10. Relation between congestion toll and parking price vs. traffic performance and revenue over a typical working day.

Increasing the relation $\frac{p_{t}}{p_{p}}$ leads to an increasing average searching time. The higher $\frac{p_{t}}{p_{p}}$, the lower is $p_{p}$ for a fixed congestion toll, and the higher the number of drivers that decide not to use $\mathrm{P}+\mathrm{R}$ and drive into the area. The traffic 
performance impacts are more severe for low congestion tolls as drivers face less costs entering the network by car. Interestingly, the average searching time for low congestion tolls stays low up to a certain $\frac{p_{t}}{p_{p}}$ value. For example, the average searching time for $p_{t}=9$ CHF in Fig. 10a equals about $1.8-2.1$ min per car up to $\frac{p_{t}}{p_{p}}=12$ before it jumps up to $3.1 \mathrm{~min}$ per car $\left(\frac{p_{t}}{p_{p}}=30\right)$. Lower relations of $\frac{p_{t}}{p_{p}}$ and consequently, higher $p_{p}$ values lead to the highest revenue values (Fig. 10b). The total revenue results are mainly driven by the parking pricing revenue as the parking fees are charged hourly.

In summary, low relations between the congestion toll and parking pricing, $\frac{p_{t}}{p_{p}}$, might not only lead to the best traffic performance in the network, but also to the highest revenue for the city. With a higher congestion toll, $p_{t}$, the parking price, $p_{p}$, turns out to be less important for the drivers' decisions and thus, the traffic performance becomes more and more independent of the relation $\frac{p_{t}}{p_{p}}$. However, this might evoke social and political acceptability problems and changes to the drivers' behavior in the long-term. As our research focuses on short-term effects, demand changes are considered out-of-scope in this paper.

\subsection{Distributional effects of our heterogeneous VOT model}

This section investigates the capabilities of our multi-VOT framework considering several user groups associated with different VOTs. Compared to other single-VOT models, our methodology can analyze the impacts of different VOTs on the drivers' decision between entering the area by car or switching to $\mathrm{P}+\mathrm{R}$ instead. The VOT is used in our decision framework (section 2.2) to convert time-related costs into price units. In reality, the drivers' VOTs also affect their willingness to pay for parking, congestion tolls, $\mathrm{P}+\mathrm{R}$ and/or PT fees. However, here we focus on the decisions related to travel times. Thus, we relax all pricing (i.e., $p_{p}=p_{t}=p_{p r}=p_{P T}=0 \mathrm{CHF}$ ) and explore a scenario focusing on the time-related VOT impacts for different user groups.

Fig. 11 presents the percentage of drivers switching to $\mathrm{P}+\mathrm{R}$ compared to those entering the area by car.

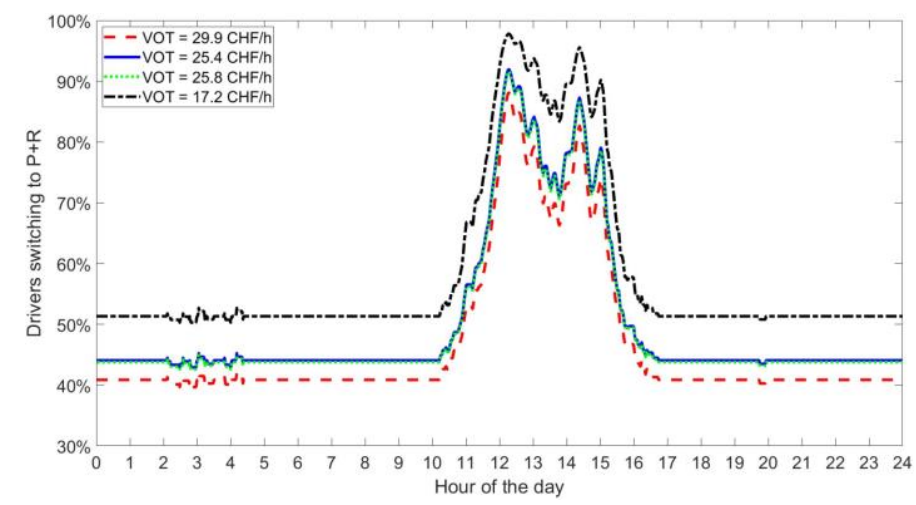

Fig. 11. Distributional effects of different VOTs on the drivers' decision between entering the area by car or switching to $\mathrm{P}+\mathrm{R}$ as a moving average over $10 \mathrm{~min}$.

Lower VOT user groups are more likely to switch to $\mathrm{P}+\mathrm{R}$. The user group associated with the lowest VOT, VOT $^{4}=$ 17.2 $\mathrm{CHF} / \mathrm{h}$, reaches the highest rate, with up to $98 \%$ of the drivers switching to $\mathrm{P}+\mathrm{R}$ during the 12.5 hour (peak of the day). This rate decreases for the drivers with a higher VOT. However, these reductions do not seem to be too drastic. This is due to significant increase in searching times during this peak hour, even after the lowest VOT user 
groups here switched to $\mathrm{P}+\mathrm{R}$.

\section{Conclusions}

In this paper, we develop a multimodal macroscopic traffic and parking search model that allows us to evaluate whether parking pricing can be considered as an alternative to the more controversial congestion pricing schemes, especially in areas with a high parking demand for public parking spaces. Our easy to implement methodology is based on aggregated data at the network level over time. Based on small data collection efforts and low computational costs, model outputs can be generated with a simple numerical solver and without complex simulation software. Our general framework only uses very limited data inputs, including travel demand, VOT, the traffic network, parking and $\mathrm{P}+\mathrm{R}$ capacities, and initial traffic and parking specifications. We illustrate our methodology using real data from an area within the city of Zurich, Switzerland. Below, we summarize the main contributions of this study.

- Our framework not only evaluates the short-term impacts on the traffic and parking system (i.e., traffic performance, parking availability, revenue for the city, etc.) resulting from implementing parking pricing and/or congestion pricing strategies, but also the impacts of the traffic and parking system (i.e., traffic congestion, parking pricing, etc.) on the drivers' decision between entering the area by car or using $\mathrm{P}+\mathrm{R}$ instead.

- We propose a decision model based on multiple user groups with respect to their VOT and integrate it into a multimodal macroscopic traffic and parking framework that allows us to assess different parking and congestion pricing policies. This framework allows us to analyze the impacts of different VOTs on the drivers' decision between entering the area by car or switching to $\mathrm{P}+\mathrm{R}$ instead.

- Besides comparing parking and congestion pricing scenarios, our study uses a simulation-based search algorithm to find the best relation between the parking fee and the congestion toll in order to improve the traffic performance in the network or the total revenue for the city (which could, in turn, be used to improve the $\mathrm{P}+\mathrm{R}$ facilities). Low relations between the congestion toll and parking pricing (i.e., a high enough parking fee in comparison to the congestion toll) might not only lead to the best traffic performance in the network, but also to the highest revenue for the city. However, due to the high costs for drivers actually entering the area by car, a lot of drivers might prefer staying at a $\mathrm{P}+\mathrm{R}$ facility outside the area. The traffic performance impacts might be more severe for low congestion tolls as drivers face less costs entering the network by car.

- Our results for Zurich show that parking pricing policies are indeed a viable option compared to congestion pricing, potentially leading to traffic performance improvements even if parking pricing policies only affect drivers using public parking in the area. Furthermore, parking pricing strategies are socially and politically more accepted and easier to implement than introducing a congestion toll in a metropolitan area.

Overall, the usage and contributions of the framework are far beyond the illustration in the presented case study. The framework could be extended to include tiered parking/P $+\mathrm{R}$ and congestion pricing. This scheme allows drivers to pay a low parking/P+R rate for the first hours, and then the rate jumps up significantly to promote higher parking availability and to increase turnover. Alternatively, the congestion toll might be low when you enter the area for only a limited amount of time. This ensures that cars do not stay forever in the area and congest the central streets. A further consideration is to enhance the parking fees and the congestion toll using responsive pricing schemes. The purpose of these time-dependent fees is to move the traffic demand for the central area away from the daily peak. Congestion 
pricing might be more expensive during the peak hours of the day compared to off-peak hours, and it might be free on Sundays as the example in London shows ([37], [44], [45]). In future research, parking fees might not only be dependent on the parking demand of each user group over time, but also on the available parking supply in the network ([34]). This could only affect a portion of the traffic demand, i.e., the parking fee for all parking spaces could follow a lower fixed (subsidized) charge for a portion of the demand and the remaining demand could be treated responsively, reflecting the external costs for parking. Similarly, future studies can investigate the impacts of only a portion of the demand being obliged to pay the congestion toll when entering the area. These differentiations within the traffic demand can be motivated by, e.g., the subsidy by a company or a city for their residents. In reality, drivers might prefer some parking spaces or PT stops in a central street or area of the network. Future research could investigate nonhomogeneous environments (e.g., where parking spaces or PT stops are inhomogeneously distributed) by developing different subnetworks connected to each other. Each subnetwork could have, for example, a different distribution of parking spaces and PT stops.

In summary, our model helps cities to investigate the short-term influences of both parking and congestion pricing policies on the traffic performance, and how the traffic performance in the area impacts the number of cars deciding between entering the network by car or using $\mathrm{P}+\mathrm{R}$ instead. Our framework offers quick evaluation possibilities for cities in terms of introducing new policies (e.g., $\mathrm{P}+\mathrm{R}$, parking pricing, and congestion charge) in an area and their impacts on the traffic and parking system, and the potential revenue over a defined time horizon.

\section{Acknowledgments}

M. Menendez acknowledges the support by the NYUAD Center for Interacting Urban Networks (CITIES) funded by Tamkeen under the NYUAD Research Institute Award CG001, and by the Swiss Re Institute under the Quantum Cities $^{\mathrm{TM}}$ initiative.

The authors declare that there is no conflict of interest regarding the publication of this paper.

The data used to support the findings of this study are available here. 


\section{References}

[1] Albert, G., and D. Mahalel. 2006. "Congestion tolls and parking fees: a comparison of the potential effect on travel behavior". Transport Policy, 13 (6), pp. 496-502.

[2] Ambühl, L., A. Loder, H. Becker, M. Menendez, K.W. Axhausen. 2018. "Evaluating London' congestion charge: An approach using the macroscopic fundamental diagram”. Proceedings of $7^{\text {th }}$ Transport Research Arena TRA 2018, April 16-19, 2018, Vienna, Austria.

[3] Ambühl, L., A. Loder, M. Menendez, K.W. Axhausen. 2017. "Empirical Macroscopic Fundamental Diagrams: New Insights from Loop Detector and Floating Car Data". Proceedings of the 96th Annual Meeting of the Transportation Research Board, January 8-12, 2017, Washington, D.C.

[4] Anas, A., and R. Lindsey. 2011. "Reducing urban road transportation externalities: Road pricing in theory and in practice". Review of Environmental Economics and Policy, 5, pp. 66-88, doi: 10.1093/reep/req019.

[5] Arnott, R., A. de Palma, R. Lindsey. 1991. "A temporal and spatial equilibrium analysis of commuter parking”. Journal of Public Economics, Vol. 45, Issue 3, pp. 301-335, doi: 10.1016/0047-2727(91)90030-6.

[6] Axhausen, K.W., A. König, G. Abay, J.J. Bates, M. Bierlaire. 2006. "Swiss value of travel time savings". ETH, Eidgenössische Technische Hochschule Zürich, IVT, Institut für Verkehrsplanung und Transportsysteme.

[7] Browning, R.C., E.A. Baker, J.A. Herron, R. Kram. 2006. "Effects of obesity and sex on the energetic cost and preferred speed of walking". Journal of Applied Physiology 100 (2), pp. 390-398.

[8] Button, K. 1993. “Transport, The Environment And Economic Policy”. Books, Edward Elgar Publishing, Number 69, pp. 154-156.

[9] Cao, J. 2016. “Effects of Parking on Urban Traffic Performance”. Ph.D. Dissertation No. 23527, Eidgenössische Technische Hochschule Zürich, IVT, Institute for Transport Planning and Systems.

[10] Cao, J., and M. Menendez. 2015. "System dynamics of urban traffic based on its parking-related-states". Transportation Research Part B: Methodological, 81 (3), pp. 718-736, doi: 10.1016/j.trb.2015.07.018.

[11] Cao, J., and M. Menendez. 2018. “Quantification of potential cruising time savings through intelligent parking services". Transportation Research Part A: Policy and Practice, Vol. 116, pp. 151-165, doi: 10.1016/j.tra.2018.06.010.

[12] Cao, J., M. Menendez, R. Waraich. 2019. "Impacts of the urban parking system on cruising traffic and policy development: The case of Zurich downtown area, Switzerland”. Transportation, 46 (3), pp. 883-908, doi: 10.1007/s11116-017-9832-9.

[13] Calthrop, E., S. Proost, K. van Dender. 2000. "Parking Policies and Road Pricing”. Urban Studies, Vol. 37, Issue 1, pp. 63-76, doi: $10.1080 / 0042098002294$.

[14] Carrasco, N. 2012. "Quantifying Reliability of Transit Service in Zurich, Switzerland: Case Study of Bus Line 31”. Transportation Research Record: Journal of the Transportation Research Board, Vol. 2274, Issue 1, doi: 10.3141/2274-13.

[15] Cervero, R. 1998. The Transit Metropolis: A Global Inquiry. Island Press, Washington, D.C., pp. 67-68, ISBN 978-1-55963-591-2.

[16] Daganzo, C. 2010. "Public transportation systems: Basic principles of system design, operations planning and real-time control”. Institute of Transportation Studies, University of California at Berkeley, No. UCB-ITS-CN-2010-1.

[17] Dakic, I., L. Ambühl, O. Schümperlin, M. Menendez. 2020. "On the modeling of passenger mobility for stochastic bi-modal urban corridors". Transportation Research Part C: Emerging Technologies, Vol. 113, pp. 146-163, doi: 10.1016/j.trc.2019.05.018.

[18] Dakic, I., and M. Menendez. 2018. "On the use of Lagrangian observations from public transport and probe vehicles to estimate car spacemean speeds in bi-modal urban networks". Transportation Research Part C: Emerging Technologies, Vol. 91, pp. 317-334.

[19] Eliasson, J. 2009. “A cost-benefit analysis of the Stockholm congestion charging system”. Transportation Research Part A: Policy and Practice, 43(4), pp. 468-480, doi: 10.1016/j.tra.2008.11.014.

[20] Fellmann, A., R. Ott, E. Willi. 2009. "Der Historische Kompromiss von 1996 - Erläuterungen zu Entstehung und Umsetzung“. Mobility Planning Department, City of Zurich, October 2009.

[21] Ge, Q., B. Ciuffo, M. Menendez. 2014. “An exploratory study of two efficient approaches for the sensitivity analysis of computationally expensive traffic simulation models". IEEE Transactions on Intelligent Transportation Systems, 15 (3), pp. $1288-1297$.

[22] Ge, Q., B. Ciuffo, M. Menendez. 2015. "Combining screening and metamodel-based methods: an efficient sequential approach for the sensitivity analysis of model outputs”. Reliability Engineering \& System Safety, 134 (2015), pp. 334-344. 
[23] Ge, Q., and M. Menendez. 2014. "An efficient sensitivity analysis approach for computationally expensive microscopic traffic simulation models". International Journal of Transportation, 2 (2), pp. 49-64.

[24] Ge, Q., and M. Menendez. 2017. "Extending Morris method for qualitative global sensitivity analysis of models with dependent inputs". Reliability Engineering \& System Safety, 162 (2017), pp. 28-39.

[25] Geroliminis, N., and C.F. Daganzo. 2008. "Existence of urban-scale macroscopic fundamental diagrams: Some experimental findings". Transportation Research Part B: Methodological, 42, pp. 759-770.

[26] Geroliminis, N. 2009. "Dynamics of peak hour and effect of parking for congested cities". Proceedings of the 88th Annual Meeting of Transportation Research Board, January 11-15, 2009, Washington, D.C.

[27] Geroliminis, N. 2015. "Cruising-for-parking in congested cities with an MFD representation”. Economics of Transportation 4 (3), pp. 156165.

[28] Goh, M. 2002. “Congestion management and electronic road pricing in Singapore”. Journal of Transport Geography, 10, pp. 29-38.

[29] Gu, Z., Z. Liu, Q. Cheng, M. Saberi. 2018. "Congestion pricing practices and public acceptance: A review of evidence”. Case Studies on Transport Policy, Vol. 6, Issue 1, pp. 94-101, doi: 10.1016/j.cstp.2018.01.004.

[30] Gu, Z., S. Shafiei, Z. Liu, M. Saberi. 2018. "Optimal distance- and time-dependent area-based pricing with the Network Fundamental Diagram”. Transportation Research Part C: Emerging Technologies, Vol. 95, pp. 1-28, doi: 10.1016/j.trc.2018.07.004.

[31] Griswold, A. 2019. "New York will be the first US city to charge drivers to enter its busiest areas". Quartz - Global business news and insights. Available at: https://qz.com/1584287/new-yorks-congestion-pricing-will-make-it-more-expensive-to-drive-in-manhattan/, Accessed on March $14,2020$.

[32] Hess, S., and M. Börjesson. 2019. "Understanding attitudes towards congestion pricing: a latent variable investigation with data from four cities". Transportation Letters, 11:2, pp. 63-77, doi: 10.1080/19427867.2016.1271762.

[33] Ison, S., and T. Rye. 2005. "Implementing road user charging: the lessons learnt from Hong Kong, Cambridge and Central London". Transport Reviews, Vol. 25, Issue 4, pp. 451-465, doi: 10.1080/0144164042000335788.

[34] Jakob, M., M. Menendez, J. Cao. 2018. “A dynamic macroscopic parking pricing and parking decision model”. Transportmetrica B: Transport Dynamics (2018), doi: 10.1080/21680566.2018.1488226.

[35] Jakob, M., and M. Menendez. 2019. "Macroscopic Modeling of On-Street and Garage Parking: Impact on Traffic Performance". Journal of Advanced Transportation, Volume 2019, Article ID 5793027, 20 pages, doi: 10.1155/2019/5793027.

[36] Kodransky, M., and G. Hermann. 2011. "Europe's Parking U-Turn: from Accommodation to Regulation”. Institute for Transportation and Development Policy, New York.

[37] Leape, J. 2006. “The London Congestion Charge”. Journal of Economic Perspectives, Vol. 20, No. 4, pp. 157-176, doi: 10.1257/jep.20.4.157.

[38] Loder, A., L. Ambühl, M. Menendez, K.W. Axhausen. 2017. "Empirics of multi-modal traffic networks: Using the 3D macroscopic fundamental diagram". Transportation Research Part C: Emerging Technologies, 82, pp. 88-101, doi: 10.1016/j.trc.2017.06.009.

[39] Loder, A., L. Ambühl, M. Menendez, K.W. Axhausen. 2019. “Understanding traffic capacity of urban networks". Scientific Reports, 9, 16283, doi: $10.1038 / \mathrm{s} 41598-019-51539-5$.

[40] Olszewski, P., and L. Xie. 2005. "Modelling the effects of road pricing on traffic in Singapore". Transportation Research Part A: Policy and Practice, 39(7-9), pp. 755-772, doi: 10.1016/j.tra.2005.02.015.

[41] Ortigosa, J., V. Gayah, M. Menendez. 2019. "Analysis of one-way and two-way street configurations on urban grid networks". Transportmetrica B: Transport Dynamics, 7 (9), pp. 423-445, doi: 10.1080/21680566.2017.1337528.

[42] Paipuri, M., L. Leclercq. 2020. "Bi-modal macroscopic traffic dynamics in a single region". Transportation Research Part B: Methodological, Vol. 133, pp. 257-290, doi: 10.1016/j.trb.2020.01.007.

[43] Prud'homme, R., and J.P. Bocarejo. 2005. "The London congestion charge: a tentative economic appraisal". Transport Policy, 12, pp. 279287, doi: 10.1016/j.tranpol.2005.03.001.

[44] Santos, G. 2005. "Urban Congestion Charging: A Comparison between London and Singapore”. Transport Reviews, 25(5), pp. 511-534, doi: $10.1080 / 01441640500064439$.

[45] Santos, G., and B. Shaffer. 2004. "Preliminary Results of the London Congestion Charging Scheme". Public Works Management \& Policy, 
9(2), pp. 164-181.

[46] Schaller, B. 2010. "New York City's congestion pricing experience and implications for road pricing acceptance in the United States". Transport Policy, 17(4), pp. 266-273, doi: 10.1016/j.tranpol.2010.01.013.

[47] Schweizerische Bundesbahnen SBB, SBB-CFF-FFS, 2020. Available at: https://www.sbb.ch/de/bahnhof-services/von-tuer-zu-tuer-reisen/ parkieren-bahnhof/park-and-rail.html, Accessed on March 14, 2020.

[48] Small, K.A., E.T. Verhoef, R. Lindsey. 2007. “The Economics of Urban Transportation”. 276 pages, doi: 10.4324/9780203642306.

[49] Smeed, R. J. 1968. "Traffic Studies and Urban Congestion”. Journal of Transport Economics and Policy, 2, pp. 33-70.

[50] Shoup, D.C. 2019. “The High Cost of Free Parking: Updated Edition”, A Planners Press Book, Taylor \& Francis Ltd, First published in 2011 by the American Planning Association and updated in 2019, ISBN: 978-0367092801.

[51] TFL, Transport for London, 2020. Available at: https://tfl.gov.uk/modes/driving/congestion-charge, Accessed on March 30, 2020.

[52] VBZ, Verkehrsbetriebe Zürich, Stadt Zürich. 2020. Available at: https://www.stadt-zuerich.ch/vbz/de/index/tickets/tickets/tageskarten/ tageskarten.html, Accessed on March 14, 2020.

[53] Vickrey, W.S. 1969. “Congestion theory and transportation investment”. The American Economic Review, 59, pp. 251-260, doi: 10.1126/science.151.3712.867-a.

[54] Waraich, R., and K.W. Axhausen. 2012. “Agent-Based Parking Choice Model”. Transportation Research Record: Journal of the Transportation Research Board, Vol. 2319, pp. 39-46, doi: 10.3141/2319-05.

[55] Yang, H., and H. Huang. 2005. "Mathematical and Economic Theory of Road Pricing”. Elsevier, Oxford, ISBN: 0080444873.

[56] Yang, K., M. Menendez, N. Zheng. 2019. "Heterogeneity aware urban traffic control in a connected vehicle environment: A joint framework for congestion pricing and perimeter control”. Transportation Research Part C: Emerging Technologies, Vol. 105, pp. 439-455, doi: 10.1016/j.trc.2019.06.007.

[57] Yildirimoglu, M., and N. Geroliminis. 2014. "Approximating dynamic equilibrium conditions with macroscopic fundamental diagrams”. Transportation Research Part B: Methodological, Vol. 70, pp. 186-200, doi: 10.1016/j.trb.2014.09.002.

[58] Zheng, N., and N. Geroliminis. 2013. "On the distribution of urban road space for multimodal congested networks". Transportation Research Part B: Methodological, Vol. 57, pp. 326-341, doi: 10.1016/j.trb.2013.06.003.

[59] Zheng, N., N. Geroliminis, K. Ampountolas. 2014. "A three-dimensional macroscopic fundamental diagram for mixed bi-modal urban networks". Transportation Research Part C: Emerging Technologies, Vol. 42, pp. 168-181, doi: 10.1016/j.trc.2014.03.004.

[60] Zheng, N., and N. Geroliminis. 2016. "Modeling and optimization of multimodal urban networks with limited parking and dynamic pricing". Transportation Research Part B: Methodological, Vol. 83, pp. 36-58. 